Portland State University

PDXScholar

$1-1-2011$

\title{
Who Gender-Bends and Why? A Qualitative Study of World of Warcraft
}

Clairellyn Rose Gregory

Portland State University

Follow this and additional works at: https://pdxscholar.library.pdx.edu/open_access_etds Let us know how access to this document benefits you.

\section{Recommended Citation}

Gregory, Clairellyn Rose, "Who Gender-Bends and Why? A Qualitative Study of World of Warcraft" (2011). Dissertations and Theses. Paper 421.

https://doi.org/10.15760/etd.421

This Thesis is brought to you for free and open access. It has been accepted for inclusion in Dissertations and Theses by an authorized administrator of PDXScholar. Please contact us if we can make this document more accessible: pdxscholar@pdx.edu. 
Who Gender-Bends and Why? A Qualitative Study of World of Warcraft

by

Clairellyn Rose Gregory

A thesis submitted in partial fulfillment of the requirements for the degree of

\author{
Master of Arts \\ in \\ Communication
}

Thesis Committee:

Priya Kapoor, Chair

Leslie Rill

Alma Trinidad

Portland State University

2011 


\begin{abstract}
According to a 2009 study, $68 \%$ of American households played video games (Entertainment Software Association). With this number continually on the rise, video games and their cultures are in need of further scholarly exploration. A video game of particular interest is a massive online game known as World of Warcraft, drawing over twelve million players worldwide (Blizzard Entertainment, 2010). With a cyberspacebased culture, World of Warcraft exposes its players to phenomenon that are unique to it, and thereby not easily understood through the same measures and evaluations offered by society at large. One such phenomena is that of gender, or more specifically the bending of gender by which players assume characters of the opposite gender. Although a common practice in video games like World of Warcraft, its motivations have yet to receive adequately scholarly attention. The present study seeks to explore the process of gender selection in the massive online game World of Warcraft through qualitative methods utilizing interviews, texts, and field notes. The data is then analyzed using Kellner's (2003) methods of critical analysis of media and Langian's (1975) work on thematization.
\end{abstract}




\section{Acknowledgments}

It would be impossible to name here all of the individuals who have helped me during the course of this thesis, however, there are some to whom a special debt is owed. First and foremost I would like to thank the professors of both Oregon State University and Portland State University whose encouragement, support, and high standard of scholarship inspired me throughout my academic endeavors. In particular, the knowledge, experience, and understanding of my thesis committee proved invaluable throughout the course of my thesis work, and a great debt is owed to the wonderful professors on that committee: Dr. Kapoor, Dr. Rill, and Dr. Trinidad.

Equally important are the contributions of the players of the World of Warcraft community. To my friends who were willing to share their experiences and stories, I thank you. Much of this information would not be available had it not been for them. I hope I got it right.

Outside of academia, a special debt is owed to my wonderful friends and colleagues whose ideas, questions, criticisms, and encouragement helped make this thesis what it is. I owe all of them for their immeasurable patience when I would occasionally slip-off the deep end to rant about the difficulties I had encountered, or bore them with what I felt were the most fascinating findings. Thank you Madeline Maze and Stephanie Rawlings; I think you had to take the brunt of those rants.

Finally, a special thanks go to my parents, Ron and Sue Gregory for their continual moral support. Thank you for listening, offering suggestions, occasionally forcing me out of my apartment, and helping me reorganize my forum data after it got messed up for the third time and I was ready to give up. Finally, a special debt is owed to 
my fiancée, Kim, for his immeasurable tolerance and encouragement, for taking care of the rest of life, including a messy immigration process, so I didn't have to, and for his uncountable sacrifices. 
Table of Contents

Abstract....................................................... i

Acknowledgements.................................................. ii

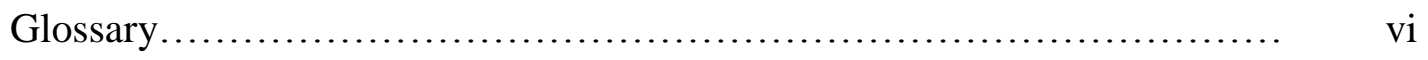

Chapter I: Introduction.......................................... 1

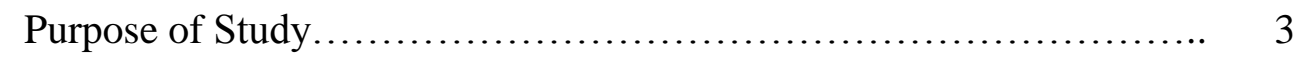

Chapter II: Literature Review....................................... 5

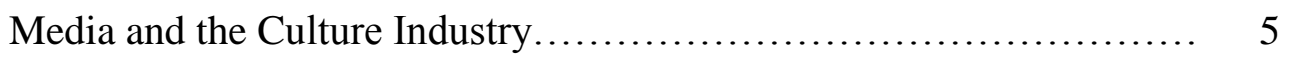

The Construction of Gender................................. 11

Gender Norms and Roles.................................... 15

Presentation and Idealized Self.............................. 17

Overview of World of Warcraft.............................. 19

The Normalization of Gender-Bending ......................... 21

Motivations for Gender Selection............................ 23

Chapter III: Methodology.......................................... 31

Methodology $\ldots \ldots \ldots \ldots \ldots \ldots \ldots \ldots \ldots \ldots \ldots \ldots \ldots \ldots \ldots \ldots \ldots \ldots, \quad 31$

Research Design........................................... 33

Data Collection........................................... 37

Data Analysis............................................ 43

Self-Reflexivity and Auto-Ethnography $\ldots \ldots \ldots \ldots \ldots \ldots \ldots \ldots \ldots \ldots . \quad 46$

Chapter IV: Data Analysis ...................................... $\quad 52$

Ethnography of Communication $\ldots \ldots \ldots \ldots \ldots \ldots \ldots \ldots \ldots \ldots \ldots \ldots, \quad 52$

Analysis................................................... 56 
Chapter V: Discussion and Conclusion.............................. 91

Trends in Gender Selection..................................... 91

Limitations.............................................. 104

Contributions................................................. 105

Future Research......................................... 106

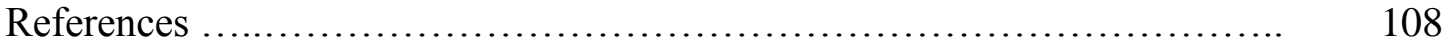

Appendices

Appendix A: Interview Guide................................ 116

Appendix B: Letter of Informed Consent........................... 117

Appendix C: Sexual Dimorphism of World of Warcraft Characters ... 118 
Glossary

Achievements: a system of points for completing certain tasks. The points do not have any value for gear or items however some do give titles that appear immediately before the player's name and riding mounts. Mostly achievement points are used as a means for bragging.

Alliance: the faction composed of humans, dwarves, gnomes, night elves, draenei, and worgen.

Arena: a form of player versus player combat that pits teams of two, three, or five against each other. Winning results in points for gear and a rating that may allow players to earn achievements or enter competitions.

Auction House: a place where players can purchase and sell goods amongst each other. Avatar: the image of the character designed by the player. In World of Warcraft, characters have certain customizable features including hair style and color, skin tone, facial design, and facial features such as piercings and tusks/horns.

Azeroth: the mythical land in which World of Warcraft takes place. It is divided into four major areas called Eastern Kingdom, Kalimdor, Outlands, and Northrend.

Bank alt: a character that is made exclusively to store items for the player.

Battlegrounds: a form of player versus player combat that pits large teams of players of each faction against each other. There are three types of battlegrounds: capture the flag (such as Arathi Basin, Twin Peaks, Battle for Gilneas, Eye of the Storm, and Warsong Gulch), a battle of resources and to kill the other teams "boss" (such as Alteric Valley 
and Isle of Conquest), and one in which one team defends while the other attacks (Strand of the Ancients).

Boss: a high level NPC usually found in a raid or dungeon. Bosses are known for their difficult fighting tactics and high level loot.

Burning Crusade (BC): the first expansion from World of Warcraft. This expansion raised the level cap to 70 and introduced the new area of Outlands, as well as new dungeons, raids, and items. Two new races were introduced in this expansion: draenei for the alliance and blood elf for the horde.

Casting Animation: the specific movements carried out by a character as they cast a spell. These animations vary by race and gender.

Cataclysm (Cata): the most recent expansion to World of Warcraft. This expansion greatly altered the appearance of Azeroth, introduced new dungeons and raids, and retooled old, low level dungeons for max level players. The level cap was also raised to 85, and a new profession (archaeology) was introduced as well as two new races (worgen for the alliance, and goblin for the horde).

Death Knight: a class of characters that utilize physical and rune-powered skills to deal damage or tank. According to lore, death knights were once the minions of an evil overlord known as the Lich King. These characters can summon ghouls to their aid. DPS: Damage Per Second; this can either be used to refer to a class of characters (those that deal damage) or a quantification of how much damage a player can do each second. Draenei: introduced in the first expansion (Burning Crusade), draenei are a mythical horse-like alien race that crashed into the land of Azeroth. 
Druid: the Swiss Army Knife of World of Warcraft; this class of characters utilize magic and physical skills to deal damage, heal, and/or tank.

Dungeon/Instance: a dungeon (also referred to as an instance) is a place where players can form groups and fight bosses and mobs. Players are awarded loot, gold, and in-game points for completing tasks such as quests and boss/mob kills, although less than that of raids and heroics. Dungeons usually consist of five players, including one tank, one healer, and three damage dealers.

Epics: a colloquial term for high level items with the best in-game powers. When moused over in-game, the item names appear in purple.

Gank: a colloquial term referring to the practice of low level players, who have few means to defend themselves, being killed by much higher level players. This can only occur on PVP servers in contested territories where players are free to attack one another. Grind: repetitively performing the same action to gather a particular item or increase reputation with a particular group.

Guild: a designated group to which players can belong. Guilds provide a means for players to socialize, develop groups for in-game activities, and various perks such as special riding mounts or abilities.

Heroics: a dungeon which is made more difficult through harder tactics or more damage dealt to players. Players are awarded gold, loot, and in-game points for completing tasks like quests and boss/mob kills, although less than that of raids. Groups are usually composed of five players including one tank, one healer, and three damage dealers. Horde: the faction composed of orcs, blood elves, tauren, undead, goblins, and trolls. This is considered to be the stereotypically "evil" side. 
Hunter: a class of characters that deal damage. Hunters are the only set of characters in the game that are able to tame animals and use them in combat.

Loot: the items that players can take off the bodies of NPCs they have killed. Some NPCs will drop better loot than others, and loot found in raids and heroics is almost always superior to that found elsewhere in the game.

Mage: a class of characters that utilize magic to do damage. This is a damage only class with little armor who relies on burst damage and slows to survive.

MMORPG: Massive Multi-player Online Role Playing Game. This is the category of games World of Warcraft falls into.

Mob: shorthand for a group of non-player enemies.

NPC: Non-Player Character; NPCs are run via game script to enact certain events or actions. Usually used in the giving of quests or individuals to be fought.

Paladin: a class of characters who use both magic and physical skills. This class can either deal damage, heal, or tank. High armor levels allow this class to take a great deal of damage.

Priest: a class of characters that utilize magic to deal damage or heal. These characters have a special set of "bubble" skills which allow them to envelope themselves or others in a protective barrier.

Professions: characters are allowed to have two primary professions (primary professions include mining, herbalism, alchemy, jewelcrafting, leatherworking, skinning, tailoring, blacksmithing, engineering, inscription, and enchanting) and all of the secondary professions (secondary professions include fishing, cooking, first aid, and 
archaeology). Professions serve as a means to provide characters with useful goods such as armor and potions, as well as a means of generating revenue.

PVP: an abbreviation for player versus player combat. Players have the opportunity to fight each other in battlegrounds, arenas, and some areas in the larger World of Warcraft. Raid: a place in which max level characters (level 85) can cooperate to take down bosses and mobs for high level loot. These places award gold, loot, and in-game points for successful completion of quests and boss kills. Raids are usually composed of 10-25 players, although previous expansions required raids as large as 40 players.

Realm/server: World of Warcraft is made up of a number of realms/servers (the two words are used interchangeably). Servers provide a means for Blizzard (the company that owns World of Warcraft) to divide the player population so as not to overload the online space available for play. There are three kinds of servers in World of Warcraft: PVP which allow players of opposing factions to attack each other in contested territories in the game at large; PVE which only allows players to fight NPCs and not attack other players except when in battlegrounds or arenas; and RP (roleplaying), made up of both PVP and PVE servers that include a greater sense of immersion in the game by the players.

Rogue: a class of characters who utilize physical attacks to deal damage. This class has a special set of skills that allow them to become invisible prior to attacking.

Shaman: a class of characters that utilize magic and physical skills to deal damage or heal. This class has a special skill set that allows them to put down totems that benefit all members of their group. 
Spam: the act of repeatedly doing something. Sometimes players will "spam" an action, such as a skill in fighting or a command from the emote system. Other times, players will "spam" something in chat, meaning they say the same thing over and over.

Tank: a character role in which the goal of the player is to keep the attention (aggro) of the monsters being fought. These characters can withstand a great deal of damage and have a high level of health. Tanking classes include warriors, paladins, and druids.

Toons: a shorthand word for a player's character or avatar.

Twink: twinks refer to low-level characters who have acquired the best low-level gear for player versus player combat. In the battleground system, players are grouped by level, with each battleground comprising nine levels (by level, battlegrounds group characters level 20-29, 30-39, 40-49, 50-59, 60-69, 70, 71-79, and 80-85). A "twink" is a character of one of the top levels for battlegrounds $(29,39,49,59,69,70$, and 79 because a max level character is not considered a "twink") who has the best possible gear for their level. These characters are virtually unstoppable by non-twink characters.

Vanilla WoW: the original World of Warcraft before the expansions.

Warlock: a class of characters that utilize magic to do damage. These characters are able to summon a minion to do their bidding and assist in damage dealing.

Wrath of the Lich King (WoTLK): the second expansion of World of Warcraft. This expansion introduced the new area of Northrend, as well as new dungeons and raids. No new races were introduced in this expansion, but certain classes were expanded to include a greater number of races. This expansion also increased the character level cap to 80 . Warrior: a class of characters that utilize physical attacks to deal damage. These characters can either tank or deal damage, and have high armor and health levels. 
Worgen: one of the new races introduced by the latest expansion, Cataclysm. This werewolf like race is a part of the alliance, and is the only race that does not require a ground mount (such as a horse) to move faster (this race descends onto all fours and runs at an increased rate). 


\section{Chapter I: Introduction}

In a world that is becoming more and more immersed in cyberspace, both for acquisition of information and social relationships, it should come as no surprise that video games are becoming more and more a part of people's everyday lives. According to a recent study by the Entertainment Software Association (ESA) (2009), 68\% of American households play video games. However, it is important to note that this statistic includes all types of video games, including those that do not allow for any sort of player interaction. This distinction is noteworthy because games that do allow for interaction provide a rich environment in which to study human interactions, especially in light of the growing amount of time individuals are spending in digital worlds rather than "real" ones. For example, in a 2004 study conducted at Michigan State University, researchers found that eighth grade boys spent an average of twenty-three hours a week playing video games, and college-aged men on the low end of the gaming spectrum spent approximately sixteen hours gaming (Greenberg, 2004). Girls devoted less time to games, with eighth grade girls spending around twelve hours gaming a week, while eleventh grade girls spent the least amount of time gaming at around six hours a week (Greenberg, 2004).

With such an increase in video game use, video games and their cultures warrant further exploration by researchers for a number of reasons. As with most new forms of media, video games have created a sort of moral panic among members of society, particularly those who are not a part of the video game community, not only because they are still relatively new and their affects are largely unknown, but because they provide different ways of seeing and understanding. Although many players see a distinct 
difference between the virtual worlds in which they play and the physical worlds in which they live, these lines continue to blur as more time is devoted to video games. This becomes especially important because of the flow of culture, and the cyclical nature of cultural influence. In this sense, cultural flow refers to the ability of a medium, such as video games, to not only reproduce cultural values, beliefs, norms, and ideologies, but to actively influence their use in the physical cultures in which they are situated (Horkheimer \& Adorno, 1969/2002). However, this flow is not unidirectional; instead, it is a cyclical process by which video games are influenced and shaped by the cultures in which they are created, and influence and shape those cultures in return. One such manner in which this influence occurs is through communication; because it is through the medium of language that individuals produce and reproduce systems of understanding about the world around them, communication plays an integral role in this transmission. As individuals talk about what it means to be a video game player and about the culture of video games, they not only produce and reproduce a system of meanings through what they say and how they say it, but actively shape both the video game culture and the larger physical culture by bringing the values of each into the cultures of both. Because of this, the discipline of communication is especially equipped to explore the phenomenon of video game culture.

Although there are a number of video game phenomenon worthy of scholarly attention, a particularly interesting one is that of gender, and specifically its reversal between the player and character (that is, players whose characters are a different sex than their own). Even though gender reversals are seen in multiple aspects of society (such as in lifestyle and professional choices), they have a unique meaning and function 
in the culture of video games. Ramet (1996) argued that each gender culture and its functions are unique and socio-historically dependent. In this sense, then, it cannot be assumed that gender and its reversal means the same thing in video games as it does in other cultures or parts of society.

\section{Purpose of Study}

Subsequently, the purpose of this study was to investigate the culture of the online role-playing game, World of Warcraft (WoW), paying specific attention to the selection of characters' genders. The goal was to explore the motivations behind the selection of a character's gender, especially the motivations behind gender-bending in particular. This game provided an ideal site for research because it attracts over twelve million players worldwide (Blizzard Entertainment, 2010) from a wide range of cultures, lifestyles, and backgrounds. Yet from these diverse backgrounds, the players create a coherent culture that is the World of Warcraft, and through which they understand one another. Additionally, unlike other games that have set characters, World of Warcraft allows players to select many of the characteristics of their avatars (see glossary), including gender, race, and skin tone, all of which have no effect on game mechanics (that is, the characters play the same with the same sets of skills regardless of gender, race, or outward appearance). With such a large and diverse player base, and a lack of game mechanics to influence gender choice, World of Warcraft represented an ideal setting to explore the notions of gender, what it means to be male or female, and what motivates players to gender-bend.

It is important to note, at this juncture, that although the term gender has had a multitude of meanings typically referring, in some fashion, to the conception of 
masculine and feminine qualities, its use in this study and preceding scholarship on gender-bending in video games takes a different approach; instead, the gender in genderbend is used to refer, first and foremost, to the swapping of sex. Utilizing the qualitative methods of interviews, texts, and field notes, I explored the World of Warcraft, questioned and listened to its members, and drew on my own experiences as a member of the World of Warcraft community to develop themes of motivation for gender selection in general, and gender-bending more specifically. The following literature review highlights the historical backdrop upon which current, critical video game scholarship is built, and offers preliminary themes of motivation. 
Chapter II: Literature Review

\section{Media and the Culture Industry}

Although the study of gender and cyberspace comes from a wide range of literature with distinct paradigmatic views and conclusions, it owes a great deal of its early work to critical scholars. Some of this literature predates the advent of the internet, but nonetheless plays an integral role in how the internet is thought to impact a wide range of phenomenon, including gender. One such foundational piece is Dialectic of Enlightenment by Horkheimer and Adorno (1969/2002). Although critical of popular and mass culture, Dialectic of Enlightenment is continually referred to for its formative work on popular culture and consumption. Originally written in 1969 to address the problems inherent to a capitalist society through the eyes of a critical scholar, Horkheimer and Adorno (1969/2002) posited the idea of a Culture Industry. To them, "all mass culture under monopoly is identical..." so much so that "film and radio no longer need to present themselves as art. The truth that they are nothing but business is used as an ideology to legitimize the trash they intentionally produce," (Horkheimer \& Adorno, 1969/2002, p. 95). In this manner, Horkheimer and Adorno (1969/2002) are arguing that the entertainment industries (at the time, largely film, radio, and television) have become a conglomerate that not only influences culture, but generates it in a manner in keeping with the economic ideals and ideologies of not only the industries to which they are a part, but to the executive powers of those industries. In an age of technology and wide spread access to the internet, the argument can easily be made from this work that the internet produces and reproduces the cultures which access it. However, this production 
is not haphazard, nor is it the work of unbiased agents seeking to simply speak their minds. Rather, the cultural production seen in cyberspace is equally driven by economic goals and ideals such as a desire to sell a product, sway opinion, or create a consumer base.

In this sense, the internet, much like the cinema and radio of the 1960s, is not free of the capitalist influences of society. Compounding this is the notion of uniformity and standardization, which is the hallmark of capitalist endeavors. Horkheimer and Adorno (1969/2002) argued that "for the present the technology of the culture industry confines itself to standardization and mass production and sacrifices what once distinguished the logic of the work from that of society" (p. 95). They continue by saying that "added to this is the agreement, or at least the common determination, of the executive powers to produce or let pass nothing which does not conform to their tables, to their concept of the consumer, or, above all, to themselves," (Horkheimer \& Adorno, 1969/2002, p. 96). For cyberspace utilizing industries, such as video game development, this conformity and recycled nature of game-play is all too true. Much like the films and television shows encountered by Horkheimer and Adorno, video games are formulaic; the characters and "plot" may vary, but it's the same basic premise: fight, kill, loot (see glossary), repeat or build, develop, repeat.

While one might argue there is still room for new development and that the entertainment industry need not continue so exclusively with its "formula," Horkheimer and Adorno would argue quite the opposite. They contend that "the explicit and implicit, exoteric and esoteric catalog of what is forbidden and what is tolerated is so extensive that it not only defines the area left free but wholly controls it. Even the most minor 
details are modeled according to this lexicon," (Horkheimer \& Adorno, 1969/2002, p. 101). In a similar line of thought, "the permanent compulsion to produce new effects which yet remain bound to the old schema, becoming additional rules, merely increases the power of the tradition which the individual effect seeks to escape," (Horkheimer \& Adorno, 1969/2002, p. 101). Again, turning to the video game industry, developers often flaunt new features such as higher levels of character customization or new forms of playing the game (for example, Wii and Playstation Move which allow the player to act out the characters' movements). However, these new features do little to change the recycled nature of game play. Furthermore, this recycling of content can be seen across the entertainment industry as a whole; games are constantly making reference to other aspects of popular culture such as movies, music, and current events. For example, World of Warcraft will often name permanent characters after movie characters, such as two NPCs (see glossary) named Mac and Samir after characters on Office Space, or a fawn named Bambina after the movie Bambi.

While this reproduction of familiar material falls into the formulaic nature of the entertainment industry, it also serves another purpose: a means of creating constant immersion. According to Horkheimer and Adorno (1969/2002):

The whole world is passed through the filter of the culture industry. The familiar experience of the moviegoer, who perceives the street outside as a continuation of the film he has just left, because the film seeks strictly to reproduce the world of everyday perception, has become the guideline of production. (p. 99)

In other words, the culture industry aims for a degree of realism in its products, something that will strike the viewer as familiar both inside the media and outside it in 
the world at large. Broadly, this can be seen in cyberspace, which seeks a certain level of immersion for its viewers through a production and reproduction of the culture in which it is a part. Similarly, video games, as part of the entertainment industry, seek to incorporate familiar material such as references to popular culture in an effort at continued immersion for its player base. In other words, even before the player enters the game, he/she is familiar with material that will appear and, perhaps more importantly, even once he/she leaves the game, they will continue to witness references supplied by the game. Furthermore, one could easily make the argument that gaming has produced its own facets of popular culture that are almost inescapable even outside the world of gaming; video games are regularly referred to in movies, on television and radio, at social events, and even in casual conversation. In this sense, what Horkheimer and Adorno argued about the entertainment industry of the late 1960s remains true today: the industries comprising the world of entertainment shape the culture of which they are a part, and generate culture of their own, thus reinforcing the system already in place. The irony of this is in the notion of such entertainment as an escape from reality. As Horkheimer and Adorno (1969/2002) put it:

It [entertainment] is sought by those who want to escape the mechanized labor process so that they can cope with it again. At the same time, however, mechanization has such power over leisure and its happiness, determines so thoroughly the fabrication of entertainment commodities, that the off-duty worker can experience nothing but after-images of the work process itself. (p. 109) Although not specifically written to address internet and video game use, this work by Horkheimer and Adorno demonstrates the applicability of critical scholarship to 
the online medium of cyberspace. It also lays the groundwork for the notion of video games as a cultural flow. Specifically, the notion of cultural flow points to the ability of a medium to not only reproduce cultural values, beliefs, norms, and ideologies, but to actively shape and influence their use and production in society at large. In their work, Horkheimer and Adorno (1969/2002) argue that radio and cinema not only reflect aspects of the culture of which they are a part, but also shape those cultures. Building upon this framework, Newcomb and Hirsch (1983) argued that television has much the same effect. Like Horkheimer and Adorno, Newcomb and Hirsch (1983) point to the importance of the producers of these cultural mediums, yet they take a decidedly less hegemonic stance. To them, producers of television are "cultural bricouleurs" who seek and create "...new meaning in the combination of cultural elements with imbedded significance. They respond to reveal events, changes in social structure and organization, and to shifts in attitude and value. They also respond to technological shift..." (Newcomb \& Hirsch, 1983, p. 563). Although at the time Newcomb and Hirsch (1983) were referring to the shift toward widespread television access, today we can see this shift occurring in internet use.

Another important distinction between the work of Horkheimer and Adorno, and the later work of Newcomb and Hirsch, is the latter's divergence from the idea of the entertainment industry as a means of oppression. Instead, they argue that television (much like other mediums of entertainment) is a comment on culture, rather than a means to force ideologies on an unsuspecting audience. To this end they argue, “...that television does not present firm ideological conclusions- despite its formal conclusionsso much as comments on ideological problems," (Newcomb \& Hirsch, 1983, p. 565-566). 
This is due, in part, to the fact that "while each of these units [specific shows] can and does present its audiences with incredibly mixed ideas, it is television as a whole system that presents a mass audience with the range and variety of ideas and ideologies inherent in American culture," (Newcomb \& Hirsch, 1983, p. 566). Like television, video games taken as a whole can be seen to provide a range of ideologies that reflect the varied nature of the cultures from which they arise.

In a similar, albeit different approach, Raymond Williams (1974/2001) argues that television is, in part, a combination of the preceding forms of communication such as radio and newspapers. However, unlike the previous means of communication, television provided an unprecedented way to reach a wide range of audiences. Horkheimer and Adorno were concerned with the ways in which this might twist and manipulate individuals' senses of reality; in fact, they argued that mediums such as cinema were meant to act and be seen as an extension of reality. Williams (1978/2003), on the other hand, believed that although television is a product of its producers, and therefore is not a neutral conduit for information, viewers are at least partially aware of this due to their consumerist nature. To Williams (1978/2003), this allows a cultural flow between the realm of the public (government, companies, policy, etc.) and the realm of the private (homes, individuals, etc.).

Likewise, video games, once relegated to the level of subculture, have emerged into the mainstream culture of America (Shaw, 2010). Sanbonmatsu (2011) contends that “...the video game is both a mirror of existing relations of power and authority in society and a powerful cultural force in its own right." Furthermore, video games can be seen as “...potent conduits of the dominant ideologies, myths, and norms of society... Like other 
forms of mass media, video games do more than just represent our world; they actively shape that world, conforming reality to particular ideologies, social expectations, and collective fantasies," (Sanbonmatsu, 2011, p. 428). In this sense, Sanbonmatsu is arguing about video games what many foregoing scholars argued about cinema and television: video games reflect and yet actively shape and re-produce the ideologies of the cultures and industries from which they arise.

Similarly, Schut's (2007) article on the use of video games as an educational tool argues, in part, that video games both reflect and influence the cultures they represent. Specifically, he makes the case that video games have a decidedly masculine bias, and reproduce historical events from that vantage point. Of this Schut (2007) says,

One of the most salient features of the digital game medium- both in terms of computer technology and the game industry itself- is that it is very masculine in nature. It should be clear that there is nothing essentially masculine about either games or computers; nevertheless, a masculine bias has been a major feature of the social construction of the digital game medium throughout its history. (p. 439) As Schut points out, there is nothing particularly masculine about the medium of computers, games, and cyberspace. Yet this has been the foundation upon which video games have been built, and thus video games, to a large extent, reflect masculine culture through the presentation of historically male-dominated fields (politics, war, etc.) and the emphasis on aggressive power and/or acquisition (Schut, 2007). Furthermore, this reflection perpetuates masculine culture and shapes the culture at large in a decidedly masculine way.

\section{The Construction of Gender}


In addition to the construction and reconstruction of culture, Lorber (1994) addresses the construction of gender. Again, this work was not aimed specifically at online culture, but certainly much can be seen to still be relevant. Lorber (1994) begins by arguing that gender is a necessary means of social organization. Not only does it deal with hierarchical relationships of power, but it impacts the very basics of conversations and interactions; that is to say, there are ways in which it is socially acceptable and unacceptable to speak, behave, and think depending upon the gender of those involved in interactions. However, this does not mean that one's sex is synonymous with one's gender, and that the notion of gender isn't made up of flexible boundaries. Similarly, Judith Butler (1988) argues that "...the body is understood to be an active process of embodying certain cultural and historical possibilities, a complicated process of appropriation..." (p. 521). Thus, rather than viewing gender as a specific set of qualities "individuals may vary on many of the components of gender and may shift genders temporarily or permanently, but they must fit into the limited number of gender statuses their society recognizes," (Lorber, 1994, p. 58). Specifically, Lorber (1994) is making the argument that although women will differ from other women, and men from other men, their gender and its enactment must still fit within the societal confines of that gender. Butler (1988) adds the additional component of historical context to this notion of the cultural construction of gender. For her, "...to be a woman is to have become a woman, to compel the body to conform to an historical idea of 'woman,' to induce the body to become a cultural sign, to materialize oneself in obedience to an historically delimited possibility, and to do this as a sustained and repeated corporeal project," (p. 522). To some extent, these confines and historical contexts can be seen as the stereotypical views 
of gender. In the world of gaming, for example, it is commonly accepted that men will be aggressive, ruthless, and will value winning and proving one's self a better gamer than others. However, although culturally accepted as male behavior, this is often seen as unlady-like, even for women competing in a male dominated arena.

Just as Butler and Lorber discuss the enacted nature of gender (that is, gender is developed through enacted behavior rather than a permanent quality based solely on anatomy) in the physical world, recent studies on video games have shown similar findings. These studies have shown that although concepts concerning gender may be different online than they are offline, there are a number of similarities because players bring their offline understandings and ways of thinking to the online world. A study of World of Warcraft demonstrated that "...there is an intricate weaving together of offline and online identity," and that gender tends to be fluid rather than fixed (Eklund, 2011, p. 332). Specifically, Eklund (2011) argued that female gamers construct their identity in such a way as to embody aspects of both masculinity and femininity, thus investing their often female characters with new and varied values. For example, some women in the study literally fought for acceptance among the male players, exhibiting masculine qualities such as competitiveness and aggression. Yet, at other times, these same players would exhibit decidedly feminine qualities such as acting as mediators for other players, or playing on Western rules of interactions to gain favors or material goods. Despite many notions about gender from the larger Western society seeping into the culture of the game, players of both genders were less limited in the construction of their identities and the mixing of feminine and masculine qualities despite the physical sex of the character (or player). Specifically, Eklund (2011) noted that many of her participants described the 
game as "...a free space; free from limitations that they perceive they have in real life," (p. 336). Because both men and women play female characters, players are able to create characters with physical feminine characteristics who embody masculine ways of behaving (Eklund, 2011).

On a similar note, Lorber (1994) also discusses the notion of gender-bending. Specifically, she argues:

If gender differences were genetic, physiological, or hormonal, gender bending and gender ambiguity would occur only in hermaphrodites, who were born with chromosomes and genitalia that are not clearly female or male. Since gender differences are socially constructed, all men and women can enact the behavior of the other, because they know the other's social script. (Lorber, 1994, p. 59) Although this article was meant to address behavior outside of virtual worlds, this argument is equally valid in online interactions. Humans need gender to organize interactions, however, in virtual worlds, "true" gender (that of the player and not the avatar) is not easily discernable. Further complicating the matter is the notion that both men and women know what the expectations and "scripts" of the other gender are, and therefore can assume the role of man or woman despite the gender they may associate themselves with in interactions outside of cyberspace. In Lorber's (1994) piece, this notion is applied to the experience of transgendered individuals. However, this is not the argument made here. Rather, virtual worlds make gender-bending easier since individuals need only assume the known scripts of the other gender; the character can easily be created, modified, or discarded as the individual chooses. This is not to say that they 
make transgendered experiences easily obtainable, but rather, as I will later discuss, have made it socially acceptable and prudent through a process of normalization.

\section{Gender Norms and Roles}

Cultures dictate a great many things: expectations for behavior, meanings and language use, customs and rituals, and social hierarchies to name but a few. So, too, do cultures form unique conceptions around gender. Ramet (1996) describes these gender cultures as “... a society's understanding of what is possible, proper, and perverse in gender-linking behavior, and more specifically, that set of values, mores, and assumptions which established which behaviors are to be seen as gender-linking...” (p. 2). However, gender cultures and their functions are not stable; they change as do the cultures in which they reside (Ramet, 1996).

It is from these gender cultures that gender roles and norms emerge. Gender norms can be seen as the set of guidelines for what constitutes masculine and feminine behavior, while gender roles can be seen as those tasks, identities, and functions deemed appropriate within the cultural confines of what it means to be men and women (Ryle, 2011). These norms and roles carry very real implications for interactions. For example, in Western culture gender norms dictate "prosocial" behaviors such as kindness, devotion, and nurturance as the accepted and expected forms of behavior for women (Eagly \& Koenig, 2006). Men, on the other hand, are socialized to be assertive, aggressive, and emotionally reserved (Eagly \& Koenig, 2006). In cross-gendered interactions, there continues to be an expectation for politeness toward and protectiveness of women. As Eagly and Koenig (2006) put it "deriving from the rules prescribed for 
medieval knights, conceptions of ideal male behavior in Western society encompass a chivalry theme..." (p. 159).

Such gender norms and roles seem to hold up, to varying degrees, in a number of video games. Fantone (2009) found that many players of the game Second Life tended to pick female avatars because the game is based loosely on the principles of good social skills and an attractive appearance, something females were seen to possess more than males (p. 219). This “...exemplifies how common assumptions on female 'qualities' in social life circulate in the game..." (Fantone, 2009, p. 219). A sample of video games analyzed by Dietz (1998) demonstrated that when female characters were present in video games, they were depicted as depending upon the male characters, thus reinforcing the overarching norm of male chivalry. Another study by Yee, Bailenson, Urbanek, Chang, and Merget (2007) showed that Second Life is “...governed by the same social norms as social interactions in the physical world," specifically those relating to gender norms and nonverbal behavior such as physical distance while talking and gaze. Such literature adds merit to the later discussion of motivations for gender selection, specifically the category of perceived gendered advantages in which players feel as though they are treated differently based on the gender of their avatar. However, it is important to note that although there are similarities between behavior on and offline, these similarities cannot be assumed because online cultures are unique from larger physical cultures. That is, although online cultures may draw from the physical cultures of which they are apart, they present unique cultures that also create their own norms, rules, and systems of understanding. 
It is within this context of gender cultures, and gender norms and roles that gender-bending is understood. As Ramet (1996) puts it:

The concept of gender culture is crucial to an understanding of the phenomenon of gender reversal, because the latter arises within the parameters set by a gender culture and because it is a society's culture that informs its members as to the meaning of specific forms of individual and collective behavior. (p. 1)

Thus, it can be seen that the gender culture of video games informs the genderbending practiced by its members. Furthermore, as gender cultures and their functions vary across contexts, it cannot be assumed that gender-bending serves the same function in video games as it serves in other facets of societies. It is precisely this function that the present study looked to examine.

\section{Presentation and Idealized Self}

In addition to conceptions about gender, video game players also tend to bring notions of presentation of self to their game-play because it is through interactions that individuals form and present their "self" to others. Goffman (1959) argues that everyone develops a role and plays their part, whether they fully believe in the role they are playing or not. It is through these masks, as he calls them, that we develop our conceptions of ourselves, and the conceptions we would like others to have of us. As Goffman (1959) puts it: "we come into the world as individuals, achieve character, and become persons," (p. 54). However, this is not to say that these masks or roles are necessarily negative, but rather one of many facets of who each person is as an individual. Often times, we strive to show the mask that is the person we would most like to be, or our idealized self. In so far as a mask "...represents the conception we have formed of ourselves- the role we are 
striving to live up to- this mask is our truer self, the self we would like to be," (Goffman, 1959, p. 54).

Video game studies have added further support to Goffman's notion of presentation of self. Williams, Kennedy, and Moore (2011) found that MMORPG (see glossary) players, especially those from marginalized groups in society at large, used avatars as a means of gaining acceptance to a community. These players tended to role play as a means of expressing facets of their personalities they felt they otherwise had to suppress in their everyday lives (Williams et al., 2011). Similarly, a study of the game Second Life found that players created avatars as a means of displaying their identity to other players (Martey \& Consalvo, 2011). In particular, Martey and Consalvo (2011) found that players tended to manage their identities primarily through physical appearance, and that most players chose distinctly male or female avatars (distinctly because they tended to have exaggerated male or female bodies with muscular, broad chests or voluptuous curves). However, unlike the previous study, this one found that players tended to make realistic characters, adhering to larger societal norms about appropriate appearances (Martey \& Consalvo, 2011). The players of this study tended to construct avatars resembling some part of the players "real" identity following both the cultural rules of the game and of Western society as a whole (Martey \& Consalvo, 2011).

Gender is arguably an important part of one's mask; it is often readily identifiable and plays a key role in the socialization process. In video games, gender can be a choice, at least much more so than in the physical world where anatomy tends to dictate the assigning of gender. Thus, disingenuous or not, gender becomes a part of players "masks" and their presentation of self to others. This is not to say that players necessarily 
identify with the gender that they are playing; in fact, players may assume identities that they themselves do not accept, sometimes with the intent to deceive others (Goffman, 1959). Such literature adds support to the following category of gender selection linked to perceived gendered advantages; specifically, this reinforces the notion that players may assume a particular gender in hopes of deceiving other players to reap perceived benefits.

However, Goffman's work also points to the creation of an idealized self. In this sense, individuals choose to display the "mask" that is closest to the self they would like to be. This provides theoretical support to the category for gender selection based on appearance. Specifically, players may select and design characters' appearances based on a conception of the "perfect" person, such as petite, attractive, muscular, strong, or noble.

\section{Overview of World of Warcraft}

The forgoing discussion provides theoretical and scholastic support for many of the concepts that will later be discussed in this study. However, equally important is a discussion of the game in which this research takes place. Although there are scholarly sources from which I could draw a basic description of the game, I would prefer to use my experience as a member of the World of Warcraft community. Like many other facets of life, World of Warcraft is not a valueless world, and certainly my interest in studying it comes from my experience as a member of the community, who has been exposed to its values and quirks, and has wondered why it is the way it is. Based on my own experience in the game over the past three years, I can say that the game is made up of essentially two groups, or factions, called the Alliance (see glossary) and the Horde (see glossary).

The Alliance tends to exemplify the "good" side with character races such as night elves, humans, gnomes, dwarves, a mythical alien/horse race known as the draenei (see 
glossary), and the recent addition of a werewolf-like race called the worgen (see glossary). The Horde, on the other hand, is made up of races typically thought of as “evil" such as undead, blood elves, orcs, trolls, goblins, and a cow-like race known as tauren. These two factions are, by the lore of the game, at odds with one another and battles are often fought between the players of the two on battle fields. Once a player has chosen a faction and a race, they choose a class. The various classes can be divided into three main categories: damage dealers (often abbreviated as “dps"), tanks, and healers (see glossary). Not surprisingly, the role of damage dealers is to deal damage to other characters (whether players or computer controlled characters) while the role of healers is to heal others. Tanks, on the other hand, mitigate damage from other players by getting the attention, or "aggro," from the attacking character. Within this basic framework, the game has a number of servers (also known as "realms;" see glossary) across the world with unique and diverse player bases, economies, and languages (both formally recognized languages such as English and Spanish, as well as modified game languages).

With this basic understanding of the game itself, a more in-depth look at the American World of Warcraft communities can be had through the examination of several recent studies. While getting to know such a culture, I would argue, requires spending some time in it, a basic introduction based on previous studies will proved an overview of the community. A 2010 study conducted by Nick Yee estimates that American World of Warcraft servers are composed of roughly $68 \%$ men and $32 \%$ women with an average age of 30.6 years. In a self-report survey, players estimated playing World of Warcraft an average of 21.4 hours a week (Yee, July 23, 2010). Although people play World of Warcraft for a number of reasons, men tended to play for the achievement component of 
the game, that is for status, domination, power, and the mechanics of the game (Yee, August 2, 2010). Women, on the other hand, tended to play for the social component of the game characterized by socializing, building and maintaining relationships, and teamwork (Yee, August 2, 2010).

\section{The Normalization of Gender-Bending}

Despite World of Warcraft's relatively recent release in 2004, gender-bending is itself not a new practice. In the early years of video game development, video games were primarily made by young men for young men (MacCallum-Stewart, 2008). Because of this largely masculine focus, it should come as no surprise that video game characters were almost exclusively male. Thus, “...there were few early female characters simply because the target demographic of games did not anticipate them as users," (MacCallumStewart, 2008, p. 29). However, it is important to note that in the beginning, players were unable to customize many, if any, aspects of the characters they played, and certainly gender was not one of those customizable features.

While female characters did begin to appear in video games over the years, the landmark game for female characters was Streetfighter II in 1986 (MacCallum-Stewart, 2008). What made this game unique was not only the design style but "... a revolutionary new style of 'special moves' which differentiated each character not simply by speed, strength or health, and demanded that the player activate a series of complicated... manipulations of buttons and joystick in order to complete each action successfully," (MacCallum-Stewart, 2008, p. 29). This means that each character had its own special set of skills and moves that allowed players to choose characters that fit their play style. For example, some characters were fast but had less powerful moves while others were 
slower with more powerful moves. Because of this players chose characters largely for their play style with few other influencing factors.

Thus, female characters were chosen not because they were female, but because the player preferred their style of play. In Streetfighter II, the hallmark female character was Chun Li, a young, energetic character dressed in a striking blue qipao who rose to popularity among gamers for her lightening fast moves (MacCallum-Stewart, 2008). It has been argued that "...Chun Li was the fastest of the characters in the game and the one whose moves were also the easiest overall to execute, although they had less relative power than most of her male counterparts..." (MacCallum-Stewart, 2008, p. 29). Thus, male players began gender-bending by choosing female characters such as Chun Li, among a number of others, for play. However, it is important to note that this was not problematic when it first began because players typically played together within each other's physical presence. Unlike today where many multiplayer games are played with other individuals over the internet, in those days internet use was not wide spread. Thus, multiplayer games took place between two or more individuals seated in the same room. In this sense, character gender raised no questions for players who were seated within view of each other where player gender was readily discernable. As MacCallum-Stewart (2008) put it:

The player who chose a woman did not exist in an imaginary limbo to their opponent; usually they were sitting or standing right next to them, presenting the player with both the physical and imagined identity of their opposition at once, and normalising [sic] the virtual/real difference. (p. 31) 
Many video games followed in these steps for years to come, providing characters with distinctive playing styles in games like Dead or Alive selling five million copies worldwide (Klepek, June 16, 2005) and Tekken, which sold 39 million copies worldwide (Purchese, June 8, 2010). However, games like Tomb Raider, which developed into a fifty billion dollar franchise encompassing ten games and two movies (McLaughlin, February 29, 2008), where the only playable character was female, began to emerge on the video game market (MacCallum-Stewart, 2008). These games set the precedence for men playing women, effectively normalizing the behavior. More recently, the advent of MMORPGs (Massive Multi-player Online Role Playing Games) such as World of Warcraft, Final Fantasy, and Second Life have allowed gamers to play customizable characters. In these settings, players must actively choose the gender of the character (it is not a feature that can be randomized using the "random" button on the character creation screen), and character gender does not affect the available skills. Thus, although previous video games have normalized gender-bending among players, newer games such as MMORPGs have forced players to choose characters' gender on criteria other than skill sets.

\section{Motivations for Gender Selection}

Drawing on some of the previously mentioned literature in addition to several new sources, gender selection in games can be seen to encompass four themes of motivation: appearance/aesthetics, fantasy/immersion/role-playing, perceived gendered advantages, and no motivation or players that simply do not care. Beginning with the simplest of these categories, some players simply regard character gender as an inconsequential feature of a game. As MacCallum-Stewart (2008) put it, "if male and 
female both have the same function, then why not choose either?" (p. 36). However, it can be argued that this is not the case for the majority of players; a study by Nick Yee (August 4, 2008) shows that players spend a significant amount of time customizing characters, including gendered features. In fact, World of Warcraft players spent an average of ten minutes a week customizing their avatars (Yee, August 4, 2008). Considering the average World of Warcraft player has played the game for 2.15 years (Yee, August 4, 2008), that's an average of approximately 18.6 hours of avatar customization over the life of game play. This demonstrates a high level of importance among players for the appearance of their avatars. Although this includes features in addition to character gender, it can still be reasonably concluded that gender is an important feature of players' presentation of self, with some players even paying real money to change the gender of their characters.

The second motivation for gender selection of avatars is appearance/aesthetics. This goes back to the previous notion about the importance placed on the appearance of one's avatar. Game designers build this importance into the game by designing aesthetically appealing characters. Nina Huntemann (2009) argued that "part of the 'oohaah' factor of a video game is its realistic portrayal of an environment, and adding animation not necessary for game play is one way to capture the fascination of players," (p. 255). Although the importance of animations and movements is evident under the theme of appearance, so are players' desires for an attractive avatar. Based on Western ideologies of "beauty," characters are designed to have attractive, sexualized body types with the female ranging from model thin to athlete thin, and the males ranging from slim to heavy body builders (Rubenstein, 2007). This emphasis is then picked up by players, 
who further elevate the importance of an attractive avatar. According to MacCallumStewart (2008):

Players argue consistently that they choose women avatars because they like to look at them, specifically because the long term nature of play in MMORPGs means that if they are going to have to look at the same avatar repeatedly they want it to be an attractive one. This is as true of women players who choose to play men, as it is of men who choose to play women. (p. 34)

These kinds of remarks have been the fodder of much scholarly feminist inquiry about the hypersexualization of female video game characters. Lara Croft of Tomb Raider, for example, was described as “...demeaning, unrealistic, a site of horrific sexual deviance, a site of playful experimentation, bionic, sadistic, and troublesome..." (MacCallum-Stewart, 2008, p. 32). However, more recent studies have shown that both men and women prefer hypersexualized characters (Waem, Larsson, \& Neren, 2005). Specifically, not only do men prefer hypersexualized female characters, but they prefer hypersexualized male characters just as women prefer hypersexualized versions of both genders. For example, women who played male avatars in a study of World of Warcraft described doing so because they found the hypersexualized male avatars to be cute or overtly sexy (MacCallum-Stewart, 2008). While there are likely a number of reasons that players prefer hypersexualized characters, one such explanation is the notion of the idealized self. According to a study by Ducheneaut, Wen, Yee, and Wadley (2009), less than $20 \%$ of World of Warcraft players reproduced physical characteristics of their actual appearance. When they explored this further through surveys, they found that female players tended to create idealized versions of themselves or others, while male players 
tended to create sexualized characters to stand out. Each of these gendered goals can be attained through hypersexualized characters, thus perhaps explaining the trend toward this type of avatar.

The third, and perhaps most researched of the motivations, is that of perceived gendered advantages. This is perhaps best summed up by Bertozzi (2008) who argued: The gender of the avatar makes absolutely no difference to the actual abilities or capabilities of the avatar. The world is constructed to be gender neutral. Players, however, are affected by the sex of the avatar in that they treat avatars differently based on their appearance. A delicate-looking female avatar will receive more offers of help and collaboration than a male ogre avatar will. Players are very sensitive to gender politics and are often very savvy about playing as a certain type of avatar when they wish to solicit different types of reactions from other players. (p. 474)

As can be seen, the categories of appearance and perceived gendered-advantages are closely related. However, perceived gendered-advantages takes appearance a step further by making the case for a shift in player behavior based on an avatar's physical appearance, and gender in particular. Many players reported perceiving female characters as receiving more help, given more social leeway, and as receiving fewer consequences for mistakes (Slagel, 2006; MacCallum-Stewart, 2008). This behavioral difference can be attributed, in large part, to overarching cultural norms. In other words, when men play against players they believe to be female, “...they are affected by a range of cultural norms including: standards of civility, their own self definition as male, and culturally 
sanctioned expressions of sexual desire," (Bertozzi, 2008, p. 474). Subsumed within these cultural norms are notions of the man as the protector (specifically of women), the immorality of male aggression toward women, and the methods of romantic advances (such as gifts, assistance, and so on). However, it is important to note that there are also overarching cultural norms that affect women (Bertozzi, 2008). These include notions of what it means to be feminine, social hierarchies of power, and the ramifications of challenging a male dominated community.

While the notion clearly exists that some players receive benefits based on avatar gender alone, it is important to note that many players feel there are also downsides to particular genders. Under the same social constraints that allow female avatars to receive benefits, there are also a number of adverse repercussions. Yee (2008) argues that “...current MMOs [Massive Multi-player Online] are no gender-inclusive utopias. There are many social and cultural constraints for women who enter these spaces," (p. 92). For example, players interviewed for his study complained that the hypersexualization of characters attracted unwanted attention. Of the hypersexualized nature of the characters, Yee (2008) says “...this [hypersexualized characters] encourages players to think about women as token spectacles rather than actual players. In fact, players are often assumed to be men unless proven otherwise," (p. 92). In the same sense that female avatars may be afforded more assistance or more social leeway, they are afforded such on the basis of being token individuals and as individuals perceived to be less skilled than the male demographic the game was largely intended for. Elaborating upon this, Yee (2008) says: Many female players have learned that it is dangerous to reveal your real-life gender in MMOs because they will be branded as incompetent and constantly 
propositioned; In other words, they must either accept the male-subject position silently, or risk constant discrimination and harassment if they reveal that they are female. (p. 93)

The final theme of motivation behind gender selection of avatars is that of fantasy/immersion/role-playing. This category argues that assuming a gender is akin to assuming a race or class within a game. That is to say, "...the normalisation [sic] of adopting a cross gendered avatar is simply seen as one of many selections, none of which have bearing on a players' actual real life orientation," (MacCallum-Stewart, 2008, p. 35). Additionally, the idea of immersion encompasses several other important motivations behind gaming in general such as role-playing, escapism, and exploration of a new place (Yee, 2008). Again, relating back to the inter-connectedness of these themes, immersion also includes, to a certain extent, customization of character (Yee, 2008) which helps to forge a connection between player and character, and deepen the immersion experience. This can be seen in a recent study by Yee, Ducheneaut, Yao, and Nelson (2011) in which players were found to default to stereotypes based on their avatars. When analyzing the stereotype that female players preferred healing classes, Yee et al. (2001) found no significant relationship between player gender and class preference. However they did find a relationship between avatar gender and class preference, demonstrating that "...the stereotype becomes true in the VW [virtual world]female characters heal more than male characters. These findings illustrate how gender differences can be socially constructed, and how gender is being produced in VWs," (Yee et al., 2011, p. 4). 
Although these themes illustrate the motivations behind gender selection, it cannot necessarily be inferred that they apply to gender selection when players choose to gender-bend. However, there is ample evidence for a number of these themes and their application to gender-bending players. Specific to the motivation of appearance, a recent study has shown that World of Warcraft players prefer the more aesthetically pleasing races (those that conform mostly close to the Western ideals of beauty such as thin or muscular frames) when they gender-bend (Yee, December 8, 2010). Of the ten available races, three (two races of elves and a horse-like race called the draenei) account for $75 \%$ of the instances in which men gender-bend, and three (two races of elves and a muscled ox-like race known as the tauren) account for the majority of instances in which women gender-bend (Yee, December 8, 2010).

In terms of perceived gendered-advantages, a pleasing appearance is often claimed, especially by men, as a reason to assume the opposite gender (MacCallumStewart, 2008). If it is in fact true, or at the very least perceived to be true, that female avatars (which are more likely to be played by females than are male avatars) receive more assistance and social leeway, then it makes sense that men might try to take advantage of this behavioral difference during game-play by assuming female avatars. However, there are also reasons under which females may assume male avatars. Not only might some women play male characters in an effort to escape the harassment and subservient status that is sometimes given to female gamers (Yee, 2008), but also to escape the possibility of extreme aggression from male players who have been beaten by female avatars (Slimmer, 2007). However, considering that less than ten percent of women gender-bend (Huh \& Williams, 2009; Yee, July 23, 2010), the question must be 
begged as to why it is a more heavily dominated male behavior. In fact, studies have shown that men are four times more likely to gender-bend in MMOs than women (Mosley \& Patrick, 2010).

As for the last two themes of motivation for gender selection of avatars (no motivation and fantasy/role-playing/immersion), little research has been done to test their application to gender-bending. Specifically, MacCallum-Stewart (2008) briefly states that some players may assume the opposite gender as a test of their ability and knowledge of the opposite gender, or as simply a part of the spectacle of role-playing under the category of fantasy/immersion (p. 35).

\section{Conclusion}

The foregoing discussion highlights the roots of the critical scholarship on popular culture, the construction of gender, gender roles and norms, and idealized self in an effort to describe some of the influences at work on video game culture. World of Warcraft is not a culture operating entirely on its own devices; rather it influences and is influenced by the cultures in which it is situated. These cultures include popular American culture, the company through which it was created, the video game industry as a whole, and the histories of each of these. Preliminary research also points to four themes behind the motivation for gender selection: appearance/aesthetics, fantasy/roleplaying/immersion, perceived gendered advantages, and no motivations. These motivations are further explored through the methods delineated in the following section. 


\section{Chapter III: Methodology}

The purpose of this study was to explore the phenomena of gender-bending in video games, specifically those video games, such as World of Warcraft, that allowed players to select the gender of their characters, and in which gender was not tied to mechanics of the game (i.e. gender did not affect game play in terms of skills or play style). More specifically, the preceding literature review highlights the previous work on gender and video games, work that has primarily relied on quantitative methods to explain who gender-bends and how often. This creates an apparent gap in the literature, begging the more qualitative question of why it is that people gender-bend. Although the literature review briefly highlights possible themes of motivation, it continues to rely, in part, on the prevailing critical notion that gender-bending in video games is akin to transgendered experimentation. Thus, the goal of the research design was to explore the motivations behind gender-bending and to question the notion that the gender cultures of video games and their functions are at all similar to gender-bending in "real" life. This exploration was done through critical, ethnographic interviews and phenomenological analysis.

\section{Methodology}

\section{Qualitative Approach}

Qualitative methods utilize emergent and naturalistic data (Patton, 2002) to examine the why and how of phenomenon. According to Becker (2001):

The point is not to prove, beyond doubt, the existence of particular relationships so much as to describe a system of relationships, to show how things hang together in a web of mutual influence or support or interdependence... to describe 
the connections between the specifics the ethnographer knows by virtue of having been there. (p. 319)

Instead of the rigid structure of quantitative methods, qualitative methods look to the data to guide the research, and are sensitive to the experiences of those under observation. Unlike quantitative research, qualitative research views knowledge and expertise as lying in the individuals being studied rather than the researcher. This epistemological approach argues that:

If we don't find out from people what meanings they are actually giving to things, we will still talk about those meanings. In that case, we will, of necessity, invent them, reasoning that the people we are writing about must have meant this or that, or they would not have done the things they did. (Becker, 2001, p. 321)

The danger in this, of course, is that researchers can make wrong assumptions, and what may look perfectly reasonable to the researcher is, in fact, not so reasonable to the members of the community under study (Becker, 2001).

This was the same approach undertaken in this research; the goal was to turn to the members of the World of Warcraft community for their knowledge and their meanings about gender-bending in video games. Qualitative research was appropriate because it facilitated the gathering of such knowledge from the community members through the use of ethnography of communication while still allowing room to examine the context from which the phenomena arises.

\section{Ethnography of Communication}

Originating in the work of Geertz, ethnography seeks to understand culture. By culture Geertz (2001) is referring to the argument that “...man is an animal suspended in 
webs of significance he himself has spun..." (p. 56). However, this is not to be confused

with the notion that culture rests in the "minds and hearts of men." Rather, Geertz (2001) argues that culture is both a private and public thing; it is the culmination of private interpretations made public through behavioral enactment as filtered through a collective system of meanings. Simply put, culture is the collective meanings used to interpret behavior. Communicating, as a behavior, is a powerful conduit for such systems of meaning; it is through language and communication that culture is produced, reproduced, and negotiated. Thus, it is through this medium that ethnographers begin to attempt to understand culture.

In the case of the present research design, ethnography was an integral part. Through field notes and open-ended interviews, I worked to uncover the culture of gender-bending in World of Warcraft as it was understood by its members.

\section{Research Design}

\section{Research Site}

World of Warcraft is a Massive Multi-player Online Role Playing Game (MMORPG) with over twelve million subscribers worldwide (Blizzard Entertainment, 2010). Taking place in the mythical land of Azeroth (see glossary), World of Warcraft is composed of two competing factions (the Horde and Alliance) who, according to lore, have been at odds for time in memoriam. Despite a time of peace, Azeroth has been wartorn for centuries as members of the factions compete for land, resources, treasure, and honor. Each faction has gathered to its side powerful leaders of the diverse races of Azeroth. Orcs, trolls, blood elves, undead, tauren, and goblins have united to form the Horde while humans, night elves, dwarves, gnomes, worgen, and draenei have come 
together for the Alliance. Players are able to create characters of particular classes (mage, warlock, paladin, warrior, rogue, druid, shaman, priest, hunter, and death knight; see glossary) within these race and faction choices, and customize appearance within the parameters of hair styles and color, facial features, skin tones, and facial piercings and/or horn shapes (when relevant). With these characters, players are able to take part in a number of online activities including questing, raiding, player versus player combat (PVP) such as battlegrounds and arenas, professions, and running dungeons, among others (see glossary).

This study utilized English-speaking players across American and European game realms for data collection. Players from both factions were used, and characters from most of the in-game races were represented in this study.

\section{Access}

World of Warcraft tends to be a closed community; that is, unless you are already a member of the community, members are unlikely to speak with you. Specifically, without a working knowledge of the game, players are apt to see researchers as an outsider and as someone ill-equipped to understand them. Players are often aware of the stigma being a "gamer" carries (stereotypically gamers are thought to be socially inept and awkward), or of how their cultural phenomenon such as gender-bending are labeled by society at large. This makes them hesitant to talk about gaming, let alone divulge their gamer identity, to those seeking to understand their culture.

As a member of the World of Warcraft community, I gained access to the participants through relationships I had already formed during three years of previous game play. Having spent most of this time on an American server, participants were 
predominantly American and Canadian. However, I was also able to recruit several Europeans who I had become acquainted with over the past seven months while playing on a European server.

\section{Data Types}

According to Patton (2001) there are three kinds of qualitative data: interviews, observations, and documents/texts. The first of these, interviews, involve open-ended questions meant to solicit in-depth answers (Patton, 2001). In keeping with the less rigid nature of qualitative research, these interviews are designed with guiding questions that leave room for further questioning based on interviewee responses. The second kind of qualitative data, observations, involves fieldwork descriptions (Patton, 2001). This is often done through ethnographic field notes, which involve the detailed description of events, actions, and contexts for later analysis (Geertz, 2001). The third kind of qualitative data, documents/texts, refers to the written texts associated with a community (Patton, 2001). In the case of this particular study, this included the use of forum responses to discussions about character/player gender in the World of Warcraft community.

Interviews. As Geertz (2001) argued, culture is a system of meanings through which individuals interpret actions. Although there are a number of ways to explore such systems, an integral method for qualitative research is ethnographic interviews. These kinds of interviews are in-keeping with qualitative work because they rely primarily on open-ended questions which “...give the informant an opportunity to answer in ways and with content that is important to him or her- not to the researcher," (Schwartzman, 1993, p. 58). A total of ten interviews were conducted with past and present World of Warcraft 
players across American and European servers. Despite the large player base, ten interviews were deemed sufficient when coupled with over five hundred forum posts, thirty samples of fan art, and twenty hours of field notes.

Field Notes. In order to capture the context and other details of their research, ethnographers use field notes. According to Emerson (2001), “...the foundational task of ethnography is to describe the specific 'meaningful structures' through which local actors produce, perceive and interpret their own and others' actions," (p. 33). This is accomplished through thick description in which ethnographers interpret the actions and events of the group under study. Specifically, "given the commitment to local meanings, the key to thick description lies not in reporting, collecting, and assembling 'facts,' but in interpretively understanding and representing the subtleties and complexities of meaning," (Emerson, 2001, p. 33).

In connection with this study, I observed online behavior while playing World of Warcraft and took twenty hours of detailed notes about what was said and how players interacted. Some of this was specific to the notion of gender and its online construction, while other notes detailed the general norms, language, sights, and game play experiences.

Texts. In a world in which most of the communication is text based, texts become an important part of the production and reproduction of the culture of World of Warcraft. In the traditional sense, texts refer to the official documents of a group, things like posters, memos, and articles (Patton, 2001). However, World of Warcraft is anything but a traditional community; it operates in the confines of cyberspace where players are insulated from such materials. This is not to say, of course, that the company that owns 
World of Warcraft does not produce such texts, but rather that they are indicative of the business side of the video game industry, not the culture created by the players. In order to understand the culture of World of Warcraft, one must look at the cultural rhetoric generated by the players.

To do this, this study looked at the official online forums available to World of Warcraft players. These forums allowed for discussions on a wide range of topics, including gender-bending and its motivations. The forums were housed on World of Warcraft's official website, and only allowed players with active World of Warcraft accounts to sign on using their characters to post responses or create threads. However, forums are not the only means of expression available to players. There are also sites and avenues for fan art in which players artistically depict aspects of the game. In a way, such art is telling of the culture which produces it, and these, too, were examined in terms of gender depiction for this study. Additionally, Kellner (2003) points to texts in the form of imagery in the media under analysis. Thus, the imagery provided in-game by the developers was also a source of textual analysis.

\section{Data Collection}

\section{Interviews}

Interviews were one of several forms of data collection in this study. Two pilot interviews were conducted with my fiancée and a close friend, both of whom played World of Warcraft. This allowed me to test the questions for clarity and look for any emergent data that might indicate the need for more questions on particular topics. I selected my fiancée for the pilot study because he is not a native English speaker and would thus test the clarity of the questions, and both my fiancée and friend were chosen 
for their years of game experience and knowledge of the game. Both were asked to suggest any additional topics or questions that they saw absent, and adjustments were made to the interview protocol, mainly in the form of word choice to clarify and elicit more specific responses (See Appendix A for final interview protocol).

\section{Sample Participants and Size}

This study explored gender and gender-bending in World of Warcraft from the perspective of players from Western cultures, which included both American and European game servers. In order to do this, I conducted ten interviews via the audio and video chat program Skype. The interviews lasted between five and fifteen minutes, and asked interviewees to respond to eight open-ended questions. Sometimes follow-up questions were asked to elicit clarification or elaboration.

The interviewees were recruited through a snowball sampling method; I began by recruiting and interviewing players I personally knew, and branched out using their recommendations for other individuals. This allowed me to recruit not only a diverse group of people across multiple servers, but also allowed me to follow lines of knowledge and expertise, that is, who players saw as "authorities" on the topic under investigation.

General guidelines for recruitment required participants to be over the age of eighteen and speak English fluently. With statistics showing the average gamer to be thirty-five years old (ESA, 2009), it was deemed unnecessary to include minors in the present study. Furthermore, it was felt their conceptions of gender, and thus gender reversals, would be less rigidly formed than those of older players who were more likely to have strong opinions and separate conceptions of gender on and offline. This 
distinction was important for the examination of gender roles and the possible parallel nature between the "real" world and cyberspace. As someone who speaks predominantly English, it was also deemed necessary that interviewees spoke English at an almost fluent level. Although largely a given on American servers, this became an important factor on the European servers where there was a great mix of languages (predominantly Scandinavian languages for the European server I recruited from).

The interviews were conducted predominantly via the audio and video chat program Skype, although two were done via text as the participants lacked the proper audio equipment. The questions asked participants to reflect on the gender choice of their characters, why they did or did not choose to participate in gender-bending, and how they viewed others who played characters of the opposite gender in addition to how they felt they were perceived by others for their gender choice. Demographically, the interview pool consisted of all men between the ages of eighteen and thirty-three with most interviewees falling somewhere in the mid to upper twenties. Of the ten interviewees, six were Americans, one was Canadian, and three were Europeans (one each from Norway, Sweden, and England). All of the players described playing World of Warcraft off and on at least since the first expansion in 2007 , with many playing since the original release of the game in 2004. Because none of the players described playing continuously, it was hard for them to say exactly how many years they had played in total. In terms of types of players, the interviewees ranged from hardcore gamers (playing four or more hours a day and raiding at least three times a week) to casual (playing recreationally for a few hours a day without raiding). However, many of these players described being more than one 
type of gamer over the course of their time with World of Warcraft; many described having been hardcore gamers in the past who preferred more casual play now.

\section{Interview Process}

Interviews began after Human Subjects Research Review Committee (HSRRC) clearance was received on June $1^{\text {st }}, 2011$. Prior to HSRRC approval, I began recruiting possible interviewees whom I contacted again after approval was received. These interviewees joined me on Skype and were asked via video and/or audio chat for their permission to record prior to the interview. Interviewees were asked eight open-ended questions (excluding demographics) about their character selection process (specifically gender), the effects of gender on their interactions, and how they perceived the gender of other players' avatars in addition to how they felt they were perceived (See Appendix A for specific questions). The interviews lasted between five and fifteen minutes. All interviews were recorded via a Skype specific software program called Skypetintin. Transcripts were generated from the interview recordings, and were typed into a Word document by myself. All documents were securely housed on a personal, password protected laptop.

\section{Participant Observation and Field Notes}

Fieldwork is an integral part of ethnographic work, and is the means through which ethnographers observe participants and generate field notes. Although not all participants were directly observable due to server differences, observations of the World of Warcraft community at large were done in an effort to achieve breadth as well as depth, and with the assumption that such a broad view would be indicative of the community in general. 
In such fieldwork the task of the ethnographer is twofold; the ethnographer has the ability to view the phenomenon of the field through a unique, theoretical and methodological lens that allows for the rigors of theoretical scrutiny while problematizing the field in a way that allows the ethnographer to see anew those taken for granted assumptions of the culture (Emerson, 2001). As a member of the World of Warcraft community, I was also able to observe through the lens of an "insider," to examine my findings and observations from the standpoint of one who understands the cultural norms and expectations being espoused by the interviewees. Although this conflicted, to some extent, with my ability to perceive the taken for granted assumptions of the community, the theoretical and methodological scrutiny allowed me to step back and problematize a community I was already familiar with.

During my fieldwork and observations, I played as a member of the World of Warcraft community, quietly documenting my observations in a Word document I constantly ran behind the game. This resulted in twenty hours of observation, mainly on the European server of Talnivarr. Most observations were conducted in the evening to early morning hours of the server (there was a nine hour time difference between my physical location in the U.S. and the European time zone in which I played) while interacting with strangers in dungeon and heroic groups (see glossary). Other observations were made about guild (see glossary) members and their discussions about gender and play experiences.

\section{Forum Posts}

In addition to interviews and field notes, forum posts were collected. These posts were particularly important because they allowed me to observe conversations about 
gender and gender-bending as they naturally occurred between members of the World of Warcraft community. To do so, I searched the official World of Warcraft forums, which only allow members with active World of Warcraft accounts, to post and respond to threads. A total of four unique forum threads, totaling over one thousand unique responses, were collected from U.S. and European forums on the official World of Warcraft website. This sample was taken randomly by selecting the relevant threads from the first two pages of results when searching with keywords like "gender" and "genderbending." Each thread addressed gender in some manner with titles like "Why dudes play on female characters?", "Why did you pick your race/gender," "Wrong gender characters, weird?" and "Research on gender and gaming." Three of these four threads came from the U.S. forums while the other appeared on the European forums.

These posts were cut apart, read individually, and preliminarily sorted as "relevant" or "irrelevant" (the "irrelevant" category were those posts that failed to address gender in the video game). The relevant posts were then carefully re-read, and preliminary groupings based on emerging themes began.

\section{Fan Art}

Fan art was seen as yet another means to tap into gamers use of their virtual environment. In particular, it offered an artistic representation of how players viewed the environment in which they played, and the characters with which they interacted. To further explore this data type, I searched the fan art pages of the official World of Warcraft website. This site compiles all styles of World of Warcraft fan art from around the world, and displays it online. With such a large volume of art, I selected a random sample by choosing the first and last image on each page for the first fifteen pages, 
resulting in thirty samples. The links to the images were saved, and each image was studied and grouped by any and all emerging themes.

\section{Data Analysis}

\section{Thematic Analysis}

Given the diverse nature of data collected through qualitative methods, thematizing provided a means form draw commonalities across the responses. Using the data collected, this study drew on the work of Richard Lanigan to find themes across the unique, individual responses.

Lanigan (1972) begins with the basic assumption that there are three levels of communication: the behavioral level in which action is symbolic, the level in which communication signifies meaning, and the level of perpetual meaning. This final level is the level of existential communication in which the assumption is made that man, in varying degrees, can “...convey his unique humanity to another person,” (Lanigan, 1972, p. 22). By this definition, Lanigan (1972) argues that existential communication is a

phenomena of personal experience. In other words, our communication is unique not only to the context in the sense of time and place, but also to every experience that constitutes our personhood. According to Lanigan (1972), drawing on the work of Merleau-Ponty, there are three necessary conditions for existential expression: someone who expresses, a "truth" which that person expresses, and someone to express it to. From these necessary conditions, the relationship can be drawn between the person as a mediator of language, the language as expressed, and the language as perceived (Lanigan, 1972). Lanigan (1972) proceeds to argue that language is not a symbol representation of an object, but rather the union of sign and signification. In other words, Lanigan is arguing that 
language is the vehicle through which humans express their experiences and give meaning based on behavior toward a particular word or phrase. In this way, language has an ability to change, to transcend a single meaning or use.

By defining language as such, Lanigan begins to build his argument for a method of analysis. Ultimately, he argues that it is through the speech act that an individual expresses his or her consciousness to another (Lanigan, 1975). Thus, "the speech act in this developing context is a reflective object of consciousness... because it is the constituted product of the person and the other in the process of translating perception into expression and vis a versa," (Lanigan, 1975, p. 27). This is not to be confused with the act of speaking, which Lanigan (1975) maintains is an internal act discernable only to oneself. Thus, methodologically speaking, it is through words that individuals articulate their experiences to others. Although he only loosely defines a speech act as the words through which one individual expresses their consciousness and experiences to another, it is reasonable to assume that Lanigan is using speech act to mean words that express themes. In the research presented here, this method allowed for an analysis of common themes of experiences by looking for similarities in emergent themes of speech acts across the interviews collected. This method, then, allowed me to identify clusters of experience common to gamers in regards to gender-bending. In essence, this method laid the ground work to make the argument that the experiences and consciousness associated with and socialized into the experience of gender manifest themselves online in video games, albeit in different ways.

\section{Political Economy}


In addition to Lanigan's (1975) work on thematization, this study utilized Kellner's (2003) method for the critical analysis of media. The first of three components for critical analysis of media, political economy, refers to the system in which the media was produced and distributed (Kellner, 2003). This has to do with who owns the means of production and distribution, and how this affects the end media product. In the case of World of Warcraft, the media (or game) is produced by a gaming company called Blizzard Entertainment. As an American company situated in the heart of the maledominated gaming (and more broadly, entertainment) industry, Kellner (2003) argues that Blizzard naturally reflects the biases, values, and ideologies of these groups in its products.

\section{Textual Analysis}

The second component of the critical analysis of media, textual analysis, looked at the texts and artifacts within the game (as designed by the game producers) to analyze how certain ideologies are formed within gaming communities (Kellner, 2003). To a certain extent, this overlaps (at least in the gaming industry) with political economy. Put differently, political economy manifests itself in ways that can also be textually analyzed. However, some of this will also manifest itself in the way the players use the texts of the game. Both of these previously mentioned links are explored in political economy and audience reception. However, this does not fully cover the category of texts. First, I think it is important to note that "texts" do not simply refer to the written scripts of the game. In fact, those are rather few and far between in World of Warcraft, and would prove insufficient in the analysis of this category. However, texts also refer to the visual 
components of a game, such as the character design. This category, then, examined the ways in which texts contribute to underlying cultural norms and ideologies.

\section{Audience Reception}

The final component of critical analysis of culture, audience reception, was explored through the previously mentioned interviews, fan art, and forum posts.

Traditionally in the world of video games, the prevailing argument has been that games acted as a means of escape from the "real world," or a source of empowerment through escapism (Kellner, 2003). While this may certainly be true for some gamers, it misses a great deal of the motivation behind gaming. Other studies (Yee, August 2, 2010) show that gamers often play for social and achievement oriented reasons in addition to the desire to escape into a fantasy world. However, this prevailing argument of escapism also misses much of the reasoning behind gender-bending and further feeds into the stereotype of gender-bending as transgendered experimentation. In this sense, then, players' feelings and experiences related to gender and game play were explored through audience reception using qualitative interviews.

\section{Self-Reflexivity and Auto-Ethnography}

Each type of research has its own measures and methods of evaluating the rigor to which phenomenon have been studied. In quantitative research, studies are evaluated through measures of validity and reliability. Although essential to research operating within the paradigmatic confines of quantitative research, these measures do not hold up well in qualitative research, which assumes that there is no single "reality" and where the understandings of group members is typically the phenomena under study. Instead, qualitative research evaluates research in terms of trustworthiness and self-reflexivity. 


\section{Trustworthiness}

In a sense, trustworthiness delineates the degree to which data can be trusted to represent the meanings and understandings of those under study. As Lincoln and Guba (1985) put it, 'in order to demonstrate 'truth value,' the naturalist must show that he or she has represented those multiple constructions adequately, that is, that the reconstructions...that have been arrived at via the inquiry are credible to the constructors of the original multiple realities," (295-296). There are several points worth noting in this definition. First, is the notion that the conclusions drawn from analysis of data represent members' meanings as close as possible to their original state. That is, conclusions should be in-keeping with members understanding, and should be interpreted as closely as possible to members' interpretations. Secondly, qualitative research presupposes the existence of multiple "realities." Thus, trustworthiness also seeks to represent these multiple views, understandings, and meanings inherent in any group of individuals.

Lincoln and Guba (1985) also note the importance of credibility within qualitative studies, arguing that credibility can be increased by carrying out research in such a way as to increase the credibility of the data and findings, as well as returning to the original constructors for verification. In terms of the present study, credibility was increased by gathering a large body of data including qualitative interviews, forum responses, fan art, and field notes to ensure that multiple "realities" were adequately represented.

Furthermore, the interviews and forum responses provided a means through which World of Warcraft community members not only had the opportunity to express meanings on their own, but to verify findings as well.

\section{Self-Reflexivitiy}


Another measure by which qualitative methods are scrutinized is that of selfreflexivity. Self-reflexivity requires the researcher to reflect upon their "personal epistemologies" and call into question how they know what they know (Patton, 2002). This includes an examination of what they know, how they came to know it, what kinds of experience or prior knowledge might influence what they know, and how they communicate what they know to others (Patton, 2002). In the present study, I detailed what I know based on responses from individuals in the World of Warcraft community. This was done, as much as possible, in the exact words of those expressing their views in an effort to stay true to their original meanings. As for my own experiences and their influence on the present research, I have detailed my perspective and some of my experiences in the following auto-ethnographic section.

\section{Auto-ethnography}

According to Ellis and Bochner (2000), an auto-ethnography “...displays multiple layers of consciousness connecting the personal and the cultural," (p. 739). In other words, auto-ethnographies are a means through which researchers can connect their own lived experiences to that of cultural investigation. However, some have argued that such an approach is self-absorbed and pulls the researcher too close to that which they wish to investigate. Although it may be true that auto-ethnography allows researchers to draw on their own experience, Ellis (1997) makes the case that researchers must be absorbed into their topics in order to write well. To this point, she says “.... a person writing autoethnography also needs to be absorbed with the world she inhabits and the processes she finds herself a part of, which also work their way into one's identity," (p. 123). 
Although not specifically an auto-ethnographic study, it is nonetheless important to mention my ties to, and my experiences within, the World of Warcraft community. As with many qualitative studies, my interest and knowledge of this topic comes from lived experience. That is to say, as a member of the World of Warcraft community for the past three years, it is my membership and my observations which have sparked my interest in gender-bending. When I first began playing World of Warcraft, I instinctively chose a female avatar. In fact, I made a human female as close to my own likeness as I could make her. Prior to World of Warcraft, I had not been a member of the video game community, and was largely unfamiliar with the notion of using a fantasy role-playing game to try out different personas. Rather, I wanted a degree of realism, and was both surprised and bewildered by the large number of people playing characters of the other gender. I had assumed that, like me, other players attempted to maintain a certain degree of realism to their game play. However, I soon discovered that it was not just all players swapping genders, but rather mostly men playing women. In fact, there seemed to be few women to be found, and players were always surprised to learn I was really female, despite what I felt was an obvious indication through my avatar design and name. It was my experience, then, that normative understandings of gender in-game, were distinct from that of the world at large; that is, what were clear indications of gender in "real" life, were not necessarily true in-game.

Throughout my years playing World of Warcraft this continued to intrigue me. Not only did I seen men who play almost only female characters, but I saw no women crossing those same boundaries to play men. In fact, the idea seemed foreign to most players, that a woman in a male dominated realm would dare to take on the persona of the 
dominant group. Admittedly, I have had only one male character, and it bothered me on such a level to play it that I could no longer do it. Perhaps growing up in a hegemonic society I feel that my gender is so intrinsically tied to my identity that it is something I am unwilling to leave behind, even in the anonymity of cyberspace. Yet certainly I know men who feel the same way.

However, playing a woman online, and truly being a woman in the male dominated world of cyberspace, has not always been easy. Certainly I have had advantages by being a woman; people can be nicer, more forgiving, more likely to give help or material goods. However, people are also more like to sexually harass, ask for pictures both of you as a whole and more specific body parts, follow you until your only option is to block them or ticket a gamer master. I have had my fair share of these experiences as well, people who have thought that my gender was a perfectly valid reason in and of itself to dog me with disgusting, sexual comments. And yet, despite the harassment, I continue to play only female characters; I continue to watch men genderbend while women do not. Three years I have observed this, occasionally asking people about their gender selection, and never really understanding what makes some genderbend and others not. It is from this perspective that I couch my own research and analysis.

\section{Conclusion}

The foregoing section highlights the use of qualitative methods for the collection of data, including open-ended interviews, forum posts, fan art, and ethnographic field notes. The data was analyzed through Kellner's methods of critical media analysis and 
Lanigan's methods of thematization. The following section details the findings of this collection and its subsequent analysis. 


\section{Chapter IV: Data Analysis}

To better study the phenomena of gender-bending in video games, data was collected using methods of ethnography of communication, such as open-ended interviews, forum response data, fan art analysis, ethnographic field notes, and texts in the form of in-game imagery. This data was then analyzed using the three components of critical analysis of media outlined by Kellner (2003): political economy, textual analysis, and audience reception. The latter category was of particular importance as it allowed the collection of data from the point of view of the members of the World of Warcraft

community. Thus, this category was itself divided using Lanigan's (1972) methodology to highlight themes of motivation for gender selection in general and specific to genderbending. These themes largely fell within the confines of the previously outlined motivations of appearance, fantasy/role-playing, perceived gendered advantages, and none, but several other motivations emerged during the course of analysis.

\section{Ethnography of Communication}

Beginning with the work of Geertz (2001), ethnography of communication seeks to understand culture. Culture, Geertz (2001) argues, is the culmination of private interpretations that have become a collective system of meanings through behavioral enactment. One such manner in which individuals enact these meanings is through communication and language. Thus, ethnography of communication seeks to study the ways in which people communicate, and subsequently produce, reproduce, and negotiate culture.

Ethnography of communication has both a methodological and analytical approach. For the purposes of this study, I chose to use only the methods espoused by this 
approach: interviews, field notes, and texts. Although ethnography of communication also offers an analytical approach through the analysis of speech events, acts, communities, and the like, I felt that an approach that looked for over-arching themes was better suited for this endeavor. Specifically, my use of written responses and images proved more difficult to analyze, and with a large-enough body of data, small units of analysis seemed less appropriate than broad themes. Thus, analysis was carried out using Kellner's (2003) method of critical media analysis and Lanigan's (1972) method of thematization.

\section{Interviews}

Geertz (2001) argued that cultures are the systems of meanings with which individuals interpret behavior and actions. Although there are a number of ways research can attempt to understand the meanings and interpretations of groups of people, ethnography of communication argues that it is important to capture such meanings from the perspectives of the community from which they arise. One such method is qualitative interviews that utilize open-ended questions in an attempt to get members to talk about their experiences and their interpretations of them.

For this study, I conducted ten interviews via the audio and video chat program Skype, two of which were done via text as the participants lacked proper equipment (both lacked microphones). The interviews asked members of the World of Warcraft community to describe their most played characters in detail, why they chose or did not choose certain genders for these characters, and how their characters' gender influenced their online interactions as well as how they viewed the gender of other players' characters. Interviewees were selected using a snowball sample method in which 
interviewees recommended others to be interviewed, thus allowing members to indicate others they felt had particular knowledge or to be of particular interest. Players were selected from American and European servers thus confining responses to Western culture. Two requirements for participation were observed in the recruitment of interviewees: interviewees must be able to speak and understand English, and must be over the age of eighteen. Each interview was transcribed by myself, and then analyzed for themes. The analysis involved highlighting and/or underlining sections of text that illustrated certain themes based on gender selection in general, selection for characters of the player's own gender and opposite gender, how they felt this was viewed by others, and how they viewed this behavior in others themselves. General demographics of the interview group included males between the ages of eighteen and thirty-three with most interviewees in the mid to upper twenties. Most of the interviewees had played World of Warcraft on and off since the original game was released in 2004 with the players who had played the least amount of time starting with the first expansion in 2007.

\section{Field Notes}

In addition to interviews, field notes were taken in an attempt to observe culture “in action." Emerson (2001) described field notes as an integral piece in the process of ethnography, allowing the researcher to capture "meaningful structures" and culture as it is enacted. Although the perspectives and interpretations of the members of the World of Warcraft community provide an essential view into the culture of the community, field notes are integral in catching these enactments as they occur.

Over the course of this study I spent approximately 300 hours in-game, both as a member of the community and as a researcher. Although not all of these hours have 
official, written field notes to go with them, it is worth mentioning as they contribute to my overall knowledge of the culture of World of Warcraft. A much smaller sample, about twenty hours, were recorded in the form of ethnographic field notes detailing player interactions, game locations, and conversations. Two interactions of particular importance were conversations recorded separately of fellow guild members discussing gender selection for their characters.

\section{Texts}

In the traditional sense, texts refer to the documents produced by a community. Typically these include items like posters, memos, and other "official" types of physical objects. In cyberspace, such objects are much harder to come by.

For this study, texts in the form of forum postings related to characters' gender selection were gathered and analyzed using Lanigan's (1972) method of thematization. Using World of Warcraft's official forums for both the U.S. and Europe, I searched for keywords such as "gender" and "gender-bending." This produced hundreds of possible forum threads and responses, which were narrowed down by reading the first two (and most relevant) pages of results and categorizing them as relevant or irrelevant. Although it is likely there are more threads than these searches produced, the result was four threads totaling just over one thousand unique responses. Again, each response was read and categorized as relevant or irrelevant to both the thread and the current topic of study resulting in 544 unique responses. These, in turn, were grouped into themes and numbered with a handful (twenty-three) falling into multiple categories. Several additional forum posts were included in data selection because, although they did not 
discuss reasons for gender selection, they illustrated other important points related to the data, such as arguments why particular behaviors were not seen as deviant.

However, "texts" in the form of fan art were also gathered and examined for what they might reflect of players' conceptions of gender. The fan art was seen as an additional means of understanding what players saw as "feminine" and "masculine," and also added more evidence to the importance placed on appearance and gender roles. A random sample (the first and last image for the first fifteen pages) of fan art was printed from World of Warcraft's official website and studied in an attempt to draw themes across the imagery.

\section{Analysis}

Data analysis began with Kellner's (2003) method of critical analysis of media. This approach utilized three components of media development and use to gain a more holistic view of a media community. For World of Warcraft specifically, these three components (political economy, textual analysis, and audience reception) highlighted the influential power of the larger cultures in which World of Warcraft is necessarily situated (such as American culture and the video game industry) and the ways in which its members use, influence, and are influenced by it. Within this framework, Lanigan's (1972) method of thematization was applied to look for emergent themes that explained both gender selection in general and the choice to gender-bend specifically.

\section{Political Economy}

The first component of Kellner's (2003) critical analysis of media was political economy. Political economy refers to the cultural system(s) in which media is produced and distributed (Kellner, 2003). Perhaps more importantly, this piece of the analytical 
process calls attention to the ways in which media is influenced by its producer. In the case of World of Warcraft, the game is influenced by its American development and production company, the male dominated culture of the video game development industry, and the largely male audience to which it is meant to appeal.

Blizzard Entertainment: An American Endeavor. Blizzard Entertainment, the company that developed and oversees World of Warcraft, was founded by three UCLA graduates in 1991 (Vella, 2008) under the name Silicon and Synapse (Fahs, 2009). After limited success developing their own games, they turned to porting games from one platform type to another (Fahs, 2009). Their big break came in 1994 with the release of Warcraft, a real-time strategy (RTS) game that revolutionized the industry (Fahs, 2009). Warcraft was a complex mix of tactical combat and base-building played out in close quarters and real-time, also adding the dimension of a multi-player option (Fahs, 2009). Their success continued with subsequent releases of the Warcraft series, the development and release of Startcraft (another RTS), Diablo (an MMO), and finally World of Warcraft (also an MMO).

Capitalist Influences. From these humble beginnings, Blizzard has grown into a billion dollar company. Merging with Activision (a console game development company) in 2008 , revenue was expected to soar at a projected $\$ 4.5$ billion a year (Vella, 2008). Entrenched in such a capitalist environment itself, it should come as no surprise that such tendencies may and do manifest themselves in the game. World of Warcraft itself has a complex economic system that varies by server, and ebbs and flows with player demand. Some, such as Rettberg (2008), have argued that World of Warcraft provides an idealized version of Western market driven economies that "... offers its players a capitalist 
fairytale in which anyone who works hard and strives enough can rise through society's ranks and acquire great wealth." He argues that it is art imitating life, and vis a versa, saying:

In a large sense the game is training a generation of good corporate citizens not only to consume well and to pay their dues, but also to climb the corporate ladder, to lead projects, to achieve goals, to earn and save, to work hard for better possessions, to play the market, to win respect from. (Rettberg, 2008, p. 20) Indeed, many interviewees spoke to the importance of "grinding" (see glossary) goods to sell or keep for their own use. Interviewee 002 remarked on this saying “... when I was level 70 and raiding it was a lot more uhm spending time farming for materials..." (June 6, 2011). After the interview had finished, interviewee 004 described spending weeks and a large sum of in-game currency acquiring supplies to make a mount that was worth approximately 30,000-60,000 gold (the highest level of in-game currency) (June 26, 2011). He has since repeated this "grind" at least two or three times (June 26, 2011). Similarly, interviewee 001 remarked in a later conversation about how he nearly ruined one server's economy and was asked to stop by Blizzard employees. In his recount, interviewee 001 recalled reading a novel about money and doing some research on stock markets. He realized that he could make a great deal of money by essentially monopolizing the market; to do this, he bought all of the available items on the auction house (see glossary) (typically potions, herbs, and enchanting materials) and put them back up for two to three times the price he had paid. Anytime someone would try to undercut him, he'd simply buy their items and re-sell them for a much higher price. In doing so, he also made deals with entire guilds to get goods at a fraction of the cost he 
was selling to other players, under the condition that those guilds did not re-sell the items themselves. With such an inflated market, players actually began reporting him to Blizzard or transferring to other servers, and Blizzard finally contacted him and asked him to cease his practices. (June 5, 2011)

The Influence of Popular American Culture. In addition to a very real capitalist economy, Blizzard also draws on popular American culture, especially that of fellow entertainment industries. Within the emote (short for emotion) system, players can command their characters to dance by typing /dance. Dances are unique to races and gender, yet each dance is drawn from popular American culture. The female goblins, for example, perform segments of Beyonce's "Single Ladies" dance, while night elf males perform Michael Jackson's “Billie Jean” moves. NPC and quest names are also typically a nod to popular American culture. In the latest expansion players complete archaeological quests for an NPC named Harrison Jones, a spin-off of Harrison Ford and Indiana Jones. Similarly, a vendor in the capital city of Shattrath named Harris Pilton (a play on the name Paris Hilton) sells relatively useless yet still expensive items, like oversized bags and decorative rings. Beyond names, there are also quests that mimic other popular culture events. In the latest expansion, there is a quest that requires players to play a mini-game similar to the popular 1980s video game Joust. This quest requires players to ride an ostrich-like bird and jump from rock platform to rock platform spearing vulture-like birds. Similarly, the latest expansion added a tribute to the popular flash game, Zombies vs. Plants. The reward for completing the five quests in the mini-game is a singing sunflower pet similar to those planted by players in the game. These are but a few of the references "hidden" in the game. A short search online will result in thousands 
of such unique references across the game's many territories, levels, quests, and NPCs. These references are commonly called "Easter Eggs," hidden "gems" meant to be discovered by players. Despite the fact that World of Warcraft has a large international audience, these references remain predominantly American. That's not to say, however, that American popular culture is lost on international players as many of them do recognize the references. However, having spent time on a European server, I have found myself having to explain these references to other players. For example, my Norwegian fiancée has never played a Legend of Zelda game and is largely unfamiliar with the series, so the quest "It's dangerous to go alone" is utterly lost on him. To him, it appears as a rather unclever quest name, and not a popular culture reference.

The Male Domination of the Video Game Industry. Outside of the larger cultural influence, companies like Blizzard Entertainment, and subsequently their products, are influenced by the culture of the video game industry. The video game industry, like many other technological industries, is historically a demographically disproportionate one. However, despite the constant push for diversification of the workforce, video game developers are still predominantly white and male. A 2005 survey of the U.S., Canada, Australia, and the U.K. found that $83.3 \%$ of respondents identified themselves as white (Goudin, 2005). The remaining 26.4\% was split between Asian, other, Hispanic/Latino, and Black respectively. Similarly, the same study showed $88.5 \%$ of respondents identifying themselves as male, with only $11.5 \%$ responding as female (Goudin, 2005). This is in-keeping with a similar study that showed women made up only ten percent of those individuals working in the game development and design industry (“She's Got Game," 2008). Because of this seeming Caucasian and masculine 
domination of video game development, the games may, in fact, reflect the views of this dominant group. World of Warcraft, for example, allows for a wide range of customization for features like skin tone, hair color, facial piercings and the like.

Although the game offers a wide range of skin tones for the players, NPCs are typically fair skinned or slightly tanned for those races whose skin tones fit within the confines of human skin colors. In my personal experience, I have yet to encounter an NPC that I would qualify as anything other than a Caucasian (ranging from quite fair skinned to tanned), although I hear tell of several supposed "Black" characters.

The White and the Beautiful. Although gender is certainly more balanced in terms of sheer numbers than race among the NPCs of Azeroth, there is still a decided male bias. Warrior and pioneering kinds of characters are typically male, while female NPCs and quest givers are typically found in homes or buildings. That's not to say that there are no strong female NPCs or "weaker" male NPCs, but that there is a decided trend toward stereotypical views of gender roles. Similarly, both sexes have a high degree of hypersexualization. A study of sexuality and video games found that “...femininity seems to be tied to aesthetical considerations, making females less race-typical and more conformational to the 'generic gender' model," (Corneliussen, 2009, para. 14). Although the males were also found to be hypersexualized, Corneliussen (2009) found that their masculinity was tied more to issues of power. These design characteristics demonstrate a stereotypical representation of the genders, with females as beautiful, fragile creatures and males as hulking, powerful adventurers.

\section{Textual Analysis}


The second component of Kellner's (2003) method explores the textual components of media as developed by the media producers. Although this may seem synonymous with written texts, this component encompasses a much larger area of analysis, including images. This is an important point, as World of Warcraft is made up of much more imagery than written word by its producers. Although World of Warcraft's mother company, Blizzard, produces a number of written texts of its own in the form of press releases, game posters and advertisements, and memos, much more telling is the imagery with which it fills the game. Specifically, this imagery illuminates two themes: the sexualization of characters and a concern for the "perfect" body.

The Beautiful Body Bias. As mentioned in the foregoing section, World of Warcraft characters are highly sexualized in their design. Even though players are allowed a level of customization, no features allow players to change the body type of their characters. Although certainly characters can be made "ugly" through selection of certain face types, hair/skin color, and facial features, none can be changed from the almost rail-thin female or excessive-body builder male body types. Rubenstein (2007) came to a similar conclusion saying “...the 'diversity' in men is whether they look like slim bodybuilders or huge ones, and for women it read much like the shallow diversity in Dove's Campaign for Real Beauty," (para. 10). Even the "less" attractive races like orc and gnome are not safe from this hypersexualization. Rubenstein (2007) notes "while races like the gnomes and orcs are closer to looking like an athletic build due to their thicker waists, they - like all the other women in the game - have an exaggerated hourglass shape that adds a distinctly sexual element to their appearance," (para. 12). Similarly, Corneliussen (2009) observes "...femininity seems to be in conflict with the 
monstrous features of the Horde races. Thus, the female Horde characters have more visually in common with the humanlike female Alliance races than with their corresponding Horde brothers," (para. 9).

However, it's not just the female characters that are sexualized by the game design. Perhaps the best illustration of the sexualization of male characters is that of the Blood Elf males. Originally, these characters were slim, and much closer in appearance to their female counterparts than the other males of the game (Rubenstein, 2007). However, in a subsequent update, Blizzard changed the design of the males making their physique much closer to that of a slim body builder displaying well muscled arms, a slim waist, and broad shoulders (Rubenstein, 2007). Although this has since been hotly debated in the World of Warcraft community, it shows a tendency toward the status quo for oversexualized male avatars.

Another interesting point brought up by Rubenstein (2007) is that of sexual dimorphism. She argues that the character models have been so overly sexualized as to defy that which could naturally occur. When speaking of the Draenei race, she explains: What stands out first about the sexes is that the male is massive: tall with unnaturally large muscles and equally large hooves. Given this build, it would not be unreasonable to expect the female of the species to be similar, but instead her slim features are closer to that of the female Blood Elf than to the male of her own species. (para. 18) (See Appendix C for character imagery)

Coneliussen (2009) reiterates this assertion, arguing that the female avatars of World of Warcraft are feminized to suit a "generic" model of the female body not all that 
removed from those of models and athletes. However, male characters face a similar bulking-up to fit idealized notions of a large, muscled male body.

This hypersexualization of characters' bodies demonstrates the relative importance placed on appearance by game developers, not to mention the importance of outright sex appeal. It also shows the trend toward an idealized body rather than a realistic one. Although players have picked up these ideologies and shaped them as they will, Blizzard has planted the ideological seeds, much like the rest of the entertainment industry, toward an idealized (and borderline unnatural) body shape.

\section{Audience Reception}

The final component, audience reception, refers to the ways in which an audience uses the media under study, with particular emphasis on the ways in which it shapes, changes, and is influenced by such media. In the case of World of Warcraft, this component explores how players use the game to expression themselves, and how they simultaneously produce, reproduce, and are influenced by its culture. Although such an analysis could encompass a wide range of phenomenon in the game such as race, class, and social hierarchies of power among realm types, this study focused specifically on gender.

However, simply eliciting responses from members of the World of Warcraft community about the construction and interpretation of gender can result in a rather disorganized heap of data. Although there are any number of unique responses that can be given to questions of gender in World of Warcraft, the work of Lanigan provided a framework with which to organize them into general themes. Lanigan (1972) argued that language is the mechanism through which humans express their meanings and 
experiences. Specifically, he points to speech acts, which he defines as “...the constituted product of the person and the other in the process of translating perception into expression and visa versa," (Lanigan, 1972, p. 25) as the primary means of methodological analysis. In this sense, Lanigan (1972) is making the case that meanings and interpretations can be organized into themes and that it is through these themes that we understand each other.

Before the collection of data began, a literature review was conducted, partially in an attempt to identify possible themes behind the selection of a character's gender by its player. Previous scholarship (Bertozzi, 2008; Ducheneaut, Wen, Yee, \& Wadley, 2009; MacCallum-Stewart, 2008; Waem, Larsson, \& Neren, 2005; Yee, 2008; Yee, Ducheneaut,Yao, \& Nelson, 2011) identified four possible themes for the selection of a character's gender in general: appearance, perceived gendered advantages, fantasy/roleplaying/game immersion, and no motivation or where gender was seen as inconsequential by the player. With these themes for motivation in mind, data collection began, both in the form of interviews and collection of forum postings. However, as themes began to emerge, several new and unexpected themes appeared as well as those previously mentioned. Furthermore, it became apparent that gender selection was context dependent, with many players citing race and class, among other things, as influencing factors.

Data Analysis: Interviews. During the ten qualitative interviews, all but one of the previously identified motivations for gender selection emerged. The only theme identified by the literature that was absent in the interviews was that of no motivations; instead, players were conscious of the selection of their characters' genders, and did so for specific reasons. The most frequently cited theme among the interviews was that of 
appearance. In addition to frequency, players explicitly placed the most emphasis on this theme. Eight of the ten interviews alluded to this motivation for the selection of their character's gender, saying:

When I switch my character from uh from a dwarf priest which is just ridiculous concept to a female human I just felt like like I looked more confident and more legitimate when I was like doing my stuff (Interviewee 003)

I I know I've probably said this on on vent or something and you heard me but the risk of sounding totally uh I don't know chauvinistic I don't want to look at a guy's ass running on my screen when I play I would much rather look at the backside of a female character and that is the only reason (Interviewee 004)

That's true I could have make her a male it's just the fact in the game goblin males look they just look ugly and they have like the ugliest ears and the ugliest nose now I kind of remind me a little of red riding hood there but uh no it's just that the female goblins just look adorable like you want to pinch their cheeks and their voice is like helium so they're kind of cute (Interviewee 001)

Of those themes previously identified in the literature, role-playing/game

immersion was the second most common. This theme referred to players who not only

used the role-playing component built into the game, but who had preconceived notions about what their character should look like, or relied on stereotypical gender roles. Two of the ten interviewees cited this motivation, stating:

He [the character] had that long hair kind of app with the beard kind of made him look like uuuh how do I describe it? I just kind of made him look kind of real not in the real sense of the real world but uh your everyday you know kind of person you know looks like a warrior or paladin so I just though it it it he seemed to fit the character well (Interviewee 007)

Eh eh basically because as I said earlier I wanted to make when saw the taurens I thought big muscular but stupid kind of like the Conan Barbarian guy and then like I have a lot of muscles but no brain kind of a funny character... And uh tauren females look too looks too innocent and too adorable can't have that when you're playing an action game have to be tough (Interviewee 001) 
The final motivation identified by the foregoing literature review was perceived gendered advantages, or the notion that players could gain advantages based on their character's gender. This was cited by only one player, who said:

I might have chosen female because I thought you got by easier like people would give you more benefit of the doubt that was probably why... when I played that that rogue I mean no no one cared you're a male rogue (Interviewee 002)

In addition to the themes identified by the literature, several new themes emerged as well. The first of these new themes was gender identification. This theme referred to players whose own gender was a major influencing factor in the selection of their character's gender. Typically, this manifested itself in players' desire to have their character's gender be the same as their own. Four of the ten interviewees alluded to this, claiming:

Why I picked my gender? Because I'm a guy (Interviewee 001) It [the selection of the character's gender] was like it it just felt like when you're filling out an application you know like like are you male or female oh I'm a male okay I pick the male character I didn't really think about it I was like oh I guess I could just use a female character and be a male I think at the time I thought that was kind of a weird mentality like I'm going to go around in a video game as a female like as as that somehow protects my socially (Interviewee 003)

Uh well I don't know I like my friend Brandon has a female character and I'm just like you're a guy like make a guy character it's kind of weird so that's why I made both of mine male (Interviewee 008)

The other new theme that emerged from the interview data was the notion of using gender as a way to create diversity or novelty, both in one's personal list of characters and in the game at large. Four of the ten interviewees citing this responding with:

I was just looking at the screen and I was like huh I can change it to a female if I want... I just did it I thought it would be a nice change I guess (Interviewee 003) 
I also like to be different and you find uhm more male characters maybe than female (Interviewee 002)

I didn't have a female character yet and so I figured why not doesn't change the game for me (Interviewee 007)

Not only did the interview data enforce most of the pre-existing motivations identified by the literature, it also highlighted new themes. These were further reinforced by the forum data, which demonstrated a similar emphasis on motivations like appearance, and highlighted the same emergent themes of diversity/novelty and gender identification.

Data Analysis: Forum Responses. In addition to interviews, 544 unique forum responses were collected on the topic of character gender selection. Unlike the interviews, five forum posters cited no motivation for the selection of the character's gender. However, based on the relatively small number of responses citing this motivation, it can be assumed that most players care about the gender of their character. Of the forum responses, the majority (330 to be exact) cited appearance as the reason for the selection of their character's gender saying:

Animations determine which gender my class will be. I can't stand the Male Nelf casting animations, so any Nelf caster I make, automatically becomes female (Apenimon, "Why dudes play," June 30, 2011)

If I'm going to stare at some character's back for x hours a day then I might aswell enjoy what I'm watching (Raizaqtx, "Why dudes play," June 29, 2011)

For me it's pretty clear, female look better than male characters. On the alliance faction, the only chars that have style are female humans and female nelfs (Abriss, "Why dudes play," June 30, 2011)

Like the interviews, the second most common previously identified theme was that of role-playing/game immersion. These forum posters cited reasons like: 
I play characters from books and the like. Hence some are male, some female. They aren't 'me', they are old friends of many years from my library and I am just extending their storylines in new ways (Morraine, "Why dudes play," June 29, 2011)

I find the night elf lore fascinating. In night elf society, the women are warriors and therefore, they are badasses. Being female IRL, that tells me being the way I am is a strength, not a weakness (Zerstoerte, "Why did you pick," Apr. 14, 2011)

See, for me, it depends on your class. I base it on stereotypes. A rogue, for example, to me, is slim and agile, thus my Night-elf-female rogue. Wilst, a, say, paladin would be large and muscular, like a Dranei-male (Nevenni, "Why dudes play," June 29, 2011)

The final pre-existing theme of motivation was that of perceived gendered advantages. These players responded, saying:

Most of my characters are guys. I get sick of people judging my female characters saying girls can't play. When I make a mistake now, people just brush it off. Sad, but true (Fuglyman, "Why did you pick," Apr. 14, 2011)

If somebody dies when you're a male healer everybody acts like it's the end of the world. If you play a female toon you can wipe a whole party and people just say stuff like "it's ok... it happens." (Attimus, "Why did you pick," Apr. 14, 2011)

When I started the game, and was crap, my male Tauren got no help whatsoever. Whereas my female Belf received offers of marriage (Mazzledust, "Why dudes play," June 29, 2011)

Similar to the interviews, the themes of diversity/novelty and gender identification also emerged in the forum data. Of these, gender identification was cited more often in the forums than that of diversity/novelty. Players citing gender identification claimed:

never played a toon of the opposite gender. I simply can not play male toons. I feel weird doing it, I don't think it's convincing (Elesabeth, "Research on gender," Nov. 25, 2010)

My character have always being male, it would be strange to playing a female. I'm not sure why exactly it just doesn't feel right at all but $95 \%$ of these female 
characters are male so I'm missing what point I guess (Snared, "Wrong gender," Dec. 2, 2010)

I feel like my character is an extension of myself so it just doesn't feel right to me to be male (Ziaki, "Why did you pick," Apr. 13, 2011)

The final theme of motivation among the forum posters was that of

diversity/novelty. Posters cited this theme, saying things like:

i had 5 lvl 80 male toons before i rolled my first female one because $\mathrm{i}$ had everyone male horde at 80 already. its just fun (Kitchwa, "Research on gender," Nov. 25, 2010)

I'm glad I did because this character was the only female dwarf on my server for quite a long time, and for longer after that I was the only Female Dwarf Priest. Even now, people crack up when I do /silly or /flirt since they either have never heard them or rarely get to hear them (Crysta, "Why did you pick," Apr. 14, 2011)

Variety, would be boring if I had only male toons (Dextrall, "Why dudes play," June 29, 2011)

Despite the different methods of collection, and the different participants for each, both the interviews and the forum data drew relatively similar conclusions. Both supported the pre-existing themes with the exception of no motivation for gender selection, demonstrating the importance placed on the selection of characters' genders. Additionally, both the interview and the forum data showed signs of new themes, specifically that of gender identification and diversity/novelty. Although the field notes do not provide support for all of these themes, they do provide support for some of them.

Data Analysis: Field Notes and Fan Art. Although it was hard to directly observe all of these motivations as they naturally occur in the game, the field notes were able to capture the importance placed on appearance, gender identification, and a case of perceived gendered advantages. In the case of appearance, a conversation started in the 
chat system of the guild I was a part of about why the guild members had chosen particular genders for their characters. One player said that although most of his characters were male, his friends consistently made female characters, citing the importance of something attractive to look at. He went on to say that he made almost exclusively male characters because he was uncomfortable with the notion of playing a female. Despite this close identification with his own gender, he continued, saying that he was unsure why he found it so troublesome to play the opposite sex.

In the same conversation, another guild mate chimed in saying that I should tell other players I am a girl (since most players assume others are men) so that I could get stuff like in-game money. Although some players believe that players are treated differently based on their character's gender, it cannot be assumed that this is always the case. However, while participating in an in-game dungeon with a number of players I did not personally I know, I witnessed perceived gendered advantages in action. Another player and myself died at the hands of a massive monster the group was fighting. When the healer went to resurrect the other player (a male mage) before me (a female mage), the other player protested saying that ladies should always be resurrected first. I pointed out that there was no way he could know my real gender, and that perhaps I was a man. He countered saying that although that may be, based on my in-game gender I should be first because it was the proper thing to do. Drawing on notions of acceptable Western behaviors and chivalry, this player reinforced the idea that players are treated differently based on their character's gender.

In addition to the field notes, the thirty samples of fan art provide further support to the importance of appearance. One picture analyzed depicts a female blood elf during 
the in-game Easter holiday. The blood elf was seen sitting on a large stone with a number of small, white rabbits and colorful Easter eggs around her feet. Her blond hair was pulled back from her face with a headband topped with two white bunny-ears. She wore a red bustier resembling the outfits worn by Playboy bunnies that showed her almost-naked buttocks and her long, thin legs. Turned slightly to the side, the artist had highlighted her curvy body featuring large breasts, a small waist, and a plump buttock. This image was one of many like it in the sample of fan art I collected demonstrating the importance placed on an attractive character. Even though the picture was an artist's conception of the character, all the artists are World of Warcraft players, and show, to some degree, how they picture the characters and how they feel they should be.

Based on the data gathered through interviews, forum responses, field notes, and fan art, six themes of motivation were identified: appearance, role-playing, perceived gendered advantages, diversity/novelty, gender identification, and no motivation. With themes the establishment of these themes, the following sections will explore them in greater detail.

Motivation: Appearance. The theme that appeared by far the most frequently across both gender selection in general and gender-bending specifically was that of appearance. Specifically 330 forum posts and eight interviews cited some form of appearance as the motivation behind the selection of their character's gender. As a theme, appearance included a wide range of rationales. Some players simply liked the physical appearance of one gender over the other. Forum poster Tereth cited aesthetic reasons sayings "to be honest, the females look better than their ugly counterparts," while Abriss said "for me it's pretty clear, female look better than male characters. On the alliance 
faction, the only chars that have style are female humans and female nelfs" ("Why dudes play," June 30, 2011). Interviewee 001 described wanting to play a goblin but disliking the males, saying "I could have make her a male it's just the fact in the game goblin males they just look ugly and they have the ugliest ears and ugliest nose..." (June 5, 2011). Similarly, poster Romelle cited aesthetics but took it a step further saying "wanted to be Horde. Wanted to be a pally. Wanted something cuter than me," ("Why did you pick," Apr. 13, 2011).

Other individuals cited character animations and movements as their reason for gender selection. Forum poster Apenimon cited this saying "animations determine which gender my class will be. I can't stand the Male Nelf casting animations, so any Nelf caster I make, automatically becomes female," with Forumtroll agreeing saying “previously I’ve tried out the casting/attacking and movement animations, of all races/classes. And found at least on horde side, females just have dumber looking animations in general," ("Why dudes play," June 30, 2011). Similarly, interviewee 009 recalled "ive [sic] tried all races and genders, but troll male has the best bow action in game, and $2^{\text {nd }}$ to that has to be male orcs," (August 8,2011 ).

Related although slightly different, some players cited the emote system (a system of commands that allow players to laugh, dance, tell jokes, and so on) of the game as a deciding factor in gender selection. For example, forum poster Shafreeyah recalled "...my reason for playing a female character is that my friend absolutely hated the sound of the female tauren crying so i [sic] gender swapped to female just to follow him around spamming /cry,” (“Why dudes play,” June 29, 2011). Similarly, Armengar said "it all 
comes to fun. For me, it's the way of movement, jokes, voices, etc," (“Why dudes play," June 29, 2011).

A Question of Sexuality. Still others cited the importance of having something nice to look at over the course of play. Forum poster Raizaqtx used this rationale saying “if I'm going to stare at some character's back for x hours a day then I might aswell enjoy what I'm watching," (“Why dudes play,” June 29, 2011). This reason was one of the most cited and many players either admitted it was an overused reason while still using it themselves, or told others to stop using it. Interestingly, this rationale highlighted a rift in the community over which was more deviant: gender-bending or playing one's own gender. Some players such as poster Gourmandises argued "I have to look at it [the character] the whole evening. I don't want to look at some ugly Human male. I wouldn't be straight if I actually liked that," (“Why dudes play," June 30, 2011). Eowynn echoed this saying "ask yourself this: What do you think look most nice? If you answer male, you're either: A) A woman. B) A self-absorbed male. C) A homosexual," ("Why dudes play," June 29, 2011). However, many players countered this arguing that it was equally strange to play the opposite gender. Sengai argued "I certainly find it weird. You might as well be playing with a barbie doll," (“Wrong gender,” Dec. 2, 2010). Others conferred, such as Frostbiyte who maintained "regarding the whole 'id [sic] rather look at a girls @!\#!\%@! For 85 levels' if your [sic] not homosexual it shouldn't be that hard to look away from a male characters@!\#@\%@!” (“Why dudes play,” June 29, 2011).

Despite the few forum arguments over the deviancy of behaviors, players seemed to view neither as particularly deviant and espoused a "play what you like" kind of view. Many questioned why it was an issue, playing either characters of the opposite or same 
gender. Jhorxia wondered "why are some dudes afraid that random people on the internet might question their sexuality if they play on a female toon?" ("Why dudes play," June 30, 2011). Others argued that character gender was a personal choice, such as Vianica who said 'I really don't understand what people's problem with it is. It's not something I would do... but that's ME. Different people are different, it's simple, so why the kerfuffle over people having different preferences?" ("Why dudes play," June 30, 2011). In fact, many of the forum responses to questions of gender centered around what the players posting did themselves and were not commentaries on others' gender selection.

Appearance: The Male/Female Player Gap. Of all the responses relating to appearance as a motivation for gender selection, aesthetics and the importance of having something attractive to look at appeared most frequently. This was true both for genderbending and the selection of one's own gender for one's character. However, these responses were much more typical for those players who identified themselves as male when selecting both male and female characters (although especially so for female characters), and much less common for those who identified themselves as women, especially among those choosing the opposite gender.

Fan Art: Another Look at the Importance of Appearance. A review of the thirty pieces of fan art collected also demonstrates the high level of importance placed on gender and appearance. Of the thirty works, twenty displayed hypersexualized images of both men and women. In this study, hypersexualization was defined as unnatural or exaggerated body proportions, a lack of clothing for women, and oversized "heroic" attire for men. For those images that depicted females, thirteen of the sixteen portrayed them as large-breasted with small waists, scantily clad with midriff and cleavage baring 
armor/robes, and enlarged eyes and lips. Men were depicted less often, making up eleven of the images. Of these eleven, eight showed signs of hypersexualization; the men were extremely muscled, broad-shouldered, and tended to wear either extremely large heroic gear or were topless.

Motivation: Fantasy and Role-playing. The second most cited motivation for gender selection dealt with issues of role-playing and immersion in a fantasy game. Some players chose to point out the obvious: World of Warcraft is, itself, marketed as a massive role-playing game. Sesshomaruxl cited this reason saying "it's a role playing game.. [sic] You play a role.. [sic] That's it," ("Research on gender," Nov. 25, 2010). Similarly, Zannia said "it's a role. This is a role playing game. The end," ("Why dudes play," June 30, 2011). Although the game itself predisposes players to role-play, players had a number of other reasons for the importance of gender in role-playing.

Some players cited a sense of empowerment or "cool" in playing a particular role. Venedria stated "there is just something cool about being big and might in a womans [sic] little body..." and "a sense of coolness that a male character would never achieve on the same level," ("Why dudes play," June 29, 2011). Many cited an inclination toward a femme fatale model, such as Kraai who said "because human female running around with two swords as big as she is destroying everything in her path with brute strength makes me fem-manly," ("Why did you pick," Apr. 13, 2010) and Helunah who made the case that "...it's fun when pink haired female gnome kicks a huge tauren death knight butt," (“Why dudes play," June 29, 2011). This response was particular prevalent among men gender-bending and almost non-existent among female players. However, some took this even a step further saying that they felt empower beating men with women, or that they 
felt the defeat was all the more humiliating for the other players. One such conversation occurred in a guild conversation and was taken down in the ethnographic field notes. The player in question was discussing the selection of his characters' genders saying that he played predominantly male characters. However, he had a female character that he loved playing because he loved the idea of a woman beating up men, and felt that it was more humiliating for those losing to him.

Despite these previous reasons, players typically cited having some sort of preconceived idea about what their character would be like or look like, and gender, among other characteristics, naturally followed. Interviewee 001 cited this rationale for one character saying "well the reason I picked a tauren paladin and the reason he looks the way he looks is because they remind me of a Minotaur and Minotaurs according to Greek mythology big strong but rather stupid hence the name and the way he looks," (June 5, 2011). Forum posts also echoed drawing on outside sources for inspiration, such as Morraine who said “...I play characters from books and the like. Hence some are male, some female. They aren't 'me', they are old friends of many years from my library and I am just extending their storylines in new ways," ("Why dudes play," June 29, 2011). Similarly, forum Cain reiterated this point, explaining:

One of my former characters were [sic] based upon the idea of creating a truly genuinely benevolent individual, a saint of sorts. Inspired by Dostoyevsky's the idiot, coupled with various poetry and music, I wanted to create Leo Myskjin, someone who walked in the Light, who's soothe weary, heal the wounded and five comfort to the hopeless. ("Why dudes play," June 29, 2011) 
This motivation was expressed by both male and female characters, both when gender-bending and playing their own gender. Similarly, other players cited in-game lore as an inspiration for the roles they created for their characters. Zerstoerte explains "I find the night elf lore fascinating. In night elf society, the women are warriors and therefore, they are badasses. Being female IRL, that tells me being the way I am is a strength, not a weakness," ("Why did you pick," Apr. 14, 2011). Similarly, Selkhet stated "love NElf lore since Warcraft III. Always had a thing for strong amazon women. And I always played a thief/rogue/assassin/stealthy thing in every RPG I ever touched," ("Why did you pick," Apr. 14, 2011). This seemed to be particularly true for the elven races of the game, with few references to other game lore aside from the race of trolls. This, too, seemed to hold true for players of both genders across all gender selection.

Another rationale under the theme of role playing is that of stereotypical gender roles. Some players argued that a particular gender fit a particular class better because of common conceptions about behaviors and qualities of each gender. Tenpointfive, for example, cited this reason noting “...I'm actually interested in playing a healer lately and logically female characters are more suited for this role, if I do make a healer i'll definitely make it female," ("Why dudes play," June 29, 2011). Referring outrightly to gender stereotyping, Nevenni argued "see, for me, it depends on your class. I base it on stereotypes. A rogue, for example, to me, is slim and agile, thus my Night-elf-female rogue. Wilst, a, say, paladin would be large and muscular, like a Dranei-male," ("Why dudes play," June 29, 2011). Although this response appeared across both genders, it was particularly prevalent among men for selection of both genders. 
Perhaps one of the most obvious, although not frequently cited, reasons was that of players on role-playing servers. Although there are several types of servers available to World of Warcraft players, role playing is often an underrated, if not slightly looked down upon, type. These servers encourage players to immerse themselves in the game and take on the role of their character. Daenardo referred to this reason saying "in the case of my server being a roleplay server... alot of males play female characters for such purposes..." (“Why dudes play," June 29, 2011). Building on this, Vashnarz explained: For me, I choose a female character because I for one am on a RP server. sure theres [sic] lots of ERP [erotic role playing]... However there are a lot [sic] of race specific RP guilds which I like to be apart of. I prefer female orc to a male orc because... i preffer [sic] not to act like a idiot an shout a lot [sic] and get drunk. ("Why dudes play," June 30, 2011)

This rationale was particular common among self-identified male players, particularly when gender-bending, and non-existent among self-identified female players.

Gender-Bending: A Process of Normalization. Several cited exposure to genderbending in other games as a motivation for its normalization, and therefore their continued inclination to play both genders. Gurtranna highlighted this saying:

Speaking as a male veteran of tabletop roleplaying games like D\&D, and a relative newcomer to WOW. I have played many many characters over the years, of different sexes and races- from male humans, to female elves, to birdmen to talking swords... The reason being-as a roleplayer taking a character of a different *\#@@@*\% or race changes your perspective. (“Why dudes play," June 29, 2011). 
Similarly, Wilycat argued 'this is a game... I don't think its [sic] strange playing a female character if you are a guy. It didn't feel strange playing Metroid or Tomb Raider either," (“Why dudes play,” June 29, 2011). Eolien reinforced this notion as well, saying “it’s a game not real life. Ever played Resident Evil 5 with a friend? Or any other game that has a female character in it? I don't look at this character to 'see things I will never have', that's sad," ("Why dudes play," June 29, 2011). With the exception of the Dungeons and Dragons reference, these players cited games that largely do not allow for the selection of a character's gender, rather the characters come with set genders, abilities, physical characteristics and so on. However, these players (predominantly male) saw video games as traditionally having components of gender-bending in terms of player and character gender, and largely view it as unproblematic.

Motivation: Perceived Gendered Advantages. Constituting one of the smaller themes of motivation, perceived gendered advantages was used only by players choosing to gender-bend and was particularly common among male players choosing females characters. Only four players who identified themselves as female chose characters of the opposite gender for perceived gendered advantages. Three of these posters felt they were seen as equals when they played male characters. Darenyon said, in reference to playing male characters, “...some guys will treat you a bit rougher, others with more respect," ("Research on gender," Nov. 25, 2010). Elaborating on this, Telaa explained "had a Blood elf female as my first main. I was tired of having a young girl seen as @\%\#*ty by most of the players," ("Why did you pick," Apr. 14, 2011). Similarly, Fuglyman argued "most of my characters are guys. I get sick of people judging my female characters 
saying girls can’t play. When I make a mistake now, people just brush it off. Sad, but true," ("Why did you pick," Apr. 14, 2011).

Other female posters described creating male characters to avoid harassment. Kheera maintained "I have male characters; I just don't get flirted with when on them," ("Research on gender," Nov. 25, 2010). This same poster spoke earlier in their post about issues of harassment saying "a male friend... was chatting with me in sympathy over a RL [real life] issue I had... and started trying to cyber. I was pretty shocked, not expecting or having provoked/suggested/flirted, and just let it go; never heard back from him..." ("Research on gender," Nov. 25, 2010). Issues of harassment can be common in the game, with many females (myself included) having experienced at least one instance of harassment. However, it did not seem to particularly deter women from playing their own gender. This is likely due, in part, to the fact that many women find they are assumed to be men regardless of the gender they play. Killercaitie recalled:

It used to annoy me that people assumed I was a guy... I thought 'I'm a girl... This is a girl \& the name is Caitie, how do you think I'm a guy?' But having met a many guys as I did that play as girl toon, I'm used to it. I get a good laugh when people ask me to get in vent, \& they are surprised by the voice they hear. ("Wrong gender," Dec. 2, 2010)

Similarly, Itslouise echoed this saying:

It's when you play on a female character and have a female name when it gets annoying that someone questions what gender you are as it is rather obvious. It is also the mentally that men say that only men play wow so I must be one! ("Why dudes play," June 30, 2011) 
Even male players showed similar beliefs with Demineon saying "silly person girls dont [sic] play wow..." ("Why did you pick," Apr. 13, 2011). Although clearly a site of frustration for female gamers trying to be recognized as such, it demonstrates that female players don't need to choose the other gender to avoid harassment; many are already assumed to be men.

Perceived Gendered Advantages: A Male Phenomena. Although not a widely used rationale by women for gender selection, many more men cited perceived gendered advantages for choosing the other gender. Interviewee 002 described making his first female character saying:

I always want to be like needed and I felt like first of all priest because they seem like they're needed and I don't know why I might have chosen a female because I thought you got by easier like people would give you more benefit of the doubt that was probably why. (June 6, 2011).

Later he discussed how he found people actually did treat him differently explaining:

When I I was a healer and like the stereotypical what you would think a girl would play I a human female priest and uhm yeah there were many times when people thought I was a girl or or wanted to talk to me... but it it does happen people think you're a girl. (June 6, 2011)

Male players in the forum reiterated these feelings citing a difference in treatment when they played female characters. Attimus described:

If somebody dies when you're a male healer everybody acts like it's the end of the world. If you play a female toon you can wipe a whole party and people just 
say stuff like 'it's ok... it happens.' You people make me sick with your sexism... but it allows me to get away with watching tv and trying to heal during a boss fight. ("Why did you pick," Apr. 14, 2011)

Similarly, Busdriver recalls making a female character, asking for help, and then just letting the other player do all the work (“Why dudes play," June 29, 2011). Mazzledust echoed this saying "when I started the game, and was crap, my male Tauren got no help whatsoever. Whereas my female Belf received offers of marriage..." ("Why dudes play," June 29, 2011).

Same Gender, Different Perceptions. Interestingly, male and female players have differing views on how the genders are treated in World of Warcraft. Fuglyman argued that people gave her male characters more of the benefit of a doubt when things went wrong, while interviewee 002 and Attimus argued just the opposite. Although players may not agree on how the genders are treated by others in-game, it's clear that many believe there is, in fact, a difference. Of those interviewed, only three said they felt that gender didn't matter, and that male characters/players and female characters/players were treated no differently. Most of those interviewed, however, felt there was a distinct difference. Interviewee 009 felt his female character wasn't treated as seriously as his males saying “ .... a few times in bgs ect, when i was goblin female its [sic] like they dont [sic] treat you serious if $\mathrm{u}$ know what i meen $\mathrm{i}$ [sic] think people think that if you play a female char then u [sic] must be female maybe??” (August 8, 2011). Other interviewees thought that women that gender-bend are seen differently than men that gender-bend. Interviewee 001 described saying that men, as the dominate group of the gaming world, make the rules. Thus, what they do is not seen as deviant while women doing the same 
would be (June 5, 2011). Similarly, interviewee 003 explained that female characters are attractive so it makes sense that men would want to play them. He elaborated saying:

Females just overall are designated to be more attractive then [sic] men are as a gender so if males want to be females it's like okay yeah I can understand wanting to look at a female but a male... a female playing a male character... it would shock me because I don't feel that that happens a lot. (June 25, 2011) A conversation taken note of in the ethnographic field notes points to one guild member's belief that female characters are, in fact, treated differently. In discussing his once male warlock whom he paid twenty-five dollars to give a gender change, he originally cited disliking the look of the robes on the character as the reason for the swap. However, he also admitted it was a bit of a social experiment; we wanted to test his conjecture that women were treated differently. He said that he found, as a female, he was treated very differently than before, receiving more help in game, more money, and even better healing in raids. My own observations in-game yielded similar results. While participating in a dungeon, myself (a female character) and another player (a male character) died. The healer began resurrecting the other player first, who was in fact closer to where the healer was standing. Before the healer could finish resurrecting him, the other player asked the healer to stop and resurrect "ladies first." With my thesis in mind, I responded with "you never know I could really be a man." The group conferred that this was a common practice and there was really no way of definitively knowing my gender, but the other character persisted saying "I know but in character here always ladys [sic] first when entering a danger zone men always foes first." 
Motivation: None. The final theme, as identified by the literature review, was that of players who simply didn't care, or felt their character's gender was inconsequential to game play. These players were certainly in the minority, with only five saying they had no motivation to choose their character's gender. Elysionne cited this saying "I have male characters and female characters, and I never had any real reason to choose the sex of the character," ("Why dudes play," June 30, 2011). Similarly, Grecadu said "... i dont [sic] know why i [sic] made them female, and i don't care about it," ("Why dudes play," June 29, 2011). Others said the gender was a function of the default character creation screen that came up, like Magnata who recalled "the gender because I was too unimaginative to change it," ("Why did you pick," Apr. 13, 2011). This theme for motivation seemed to be the outlier with almost too few responses to mention. There also seemed to be no particular trends toward player gender or gender selection.

Further Considerations for Motivation. Although the themes of motivation previously identified by the literature review were consistent with the data collected, responses began to appear that did not fit into these predefined themes. Instead, the data began to point to two new themes that motivated players, some to choose their own gender, others to choose the opposite gender. This data created two new themes which were dubbed gender identification and diversity/novelty.

Gender Identification. Gender identification was the third most popular theme overall, and was created for those players who pointed to their own gender as the deciding factor for their character's gender. This motivation was the single most cited reason for those who identified themselves as women for their character's gender choice (thirty-eight posts). Many female gamers argued that they created female characters 
because they, themselves, were female. Although most women citing this simply mentioned it in passing with no further explanation, a few posters gave a more in depth rationale. Elesabeth, for example, explained “...never played a toon of the opposite gender. I simply can not play male toons. I feel weird doing it, I don't think it's convincing..." (“Research on gender,” Nov. 25, 2010). Similarly, Menopaws stated:

I know some MMOs that make is so character creation is only based upon what sex you put when you created the account. Personally, I like it more that way. I find it odd, and pretty sure a lot of men get away from pretending to be a girl and that isn't cool... I really want to roll a male Troll, but it's so hard to put myself doing it... I have no idea why. ("Wrong gender," Dec. 2, 2010)

Several posters said they saw their character as an extension of themselves and that their gender was such an important part of their identity that they were unwilling to put it aside, even in a fantasy game. Ziaki explained “...I feel like my character is an extension of myself so it just doesn't feel right to me to be male," ("Why did you pick," Apr. 13, 2011). Similarly, Mirain said "I think as a female, for me, it's identifying with the character in some respect. I feel more inclined to enjoy it," ("Why dudes play," June 30, 2011).

Like the female players, a large amount of male players (fifty forum posts and four interviews) cited identification with their own gender as the motivation for the selection of their characters' gender. Even though many of these players recognized the common practice of gender-bending in video games, many expressed an inability to do so themselves. Snared explained "my character have always being male, it would be strange to playing a female. I'm not sure why exactly it just doesn't feel right at all but $95 \%$ of 
these female characters are male so I'm missing what point I guess," ("Wrong gender," Dec. 2, 2010). Others elaborated on this idea, offering reasons for why they felt unable to play the opposite gender. Nuus reiterated this adding:

As a roleplayer, I feel that I simply cannot put myself into seeing from a female's perspective and mindset without skewing thing with my inherent male perspective, and don't wish to do yet another 'man's idea of a woman' character' that you already see played everywhere else. ("Why did you pick," Apr. 15, 2011) Similarly, Sorreal stated "it may be boring but I like to play things I relate to in RPGs because it makes it easier to get into the story..." ("Why did you pick," Apr. 13, 2011). Others, like interviewee 008, found the practice of gender-bending strange, recalling “...my friend Brandon has a female character and I'm just like you're a guy make a guy character it's kind of weird," (July 14, 2011). Although interviewee 008 continues to find gender-bending strange even after years of playing World of Warcraft, many responses pointed to the practice as seeming deviant in the beginning and commonplace after repeated exposure (July 14, 2011). Interviewee 003 described creating his first character and selecting the gender saying:

It just felt like when you're filling out an application you know like like are you male or female oh I'm male okay I pick the male character I didn't really think about it... I could just use a female character and be a male I think at the time I thought that was kind of a weird mentality like I'm going to go around in a video game as a female like as as that somehow protects me as a girl and then I can just be an asshole anyway. (June 25, 2011) 
Asmodias described feeling similarly stating “...in the beginning it felt weird to role a female... I have since gotten over that," ("Why did you pick," Apr. 13, 2011).

Gender-Bending: A Defense of Heterosexulaity? However, there was an interesting twist to gender identification within the male community of World of Warcraft: many men explained gender-bending as a function of an intense identification with their own gender and sexual-orientation. Put simply, a number of men, including those citing appearance for the selection of their character's gender, identified so closely with being male that as a man, they had to be sexually attracted to women. Thus they could only play female characters, lest they risk being seen as "gay." Wugwug used this rationale arguing, "I'm a straight guy and I often play female characters in games that allow it. I couldn't tell you exactly why, I just like women, I guess," ("Wrong gender," Dec. 2, 2010). Although most of these rationales were placed under the theme of appearance because they most obviously fit there without risking inference beyond what the players had meant, it is still worth noting that many of these men would also fall into this theme of gender identification.

Diversity/Novelty. Diversity/novelty was created to accommodate those players who expressed a desire to play a certain gender because they, personally, did not already possess a character of that gender, or for those who chose gender based on rarely seen combinations of race, class, and gender. Kitchwa cited the former of these reasons saying "I [sic] had 5 lvl 80 male toons before i [sic] rolled my first female one because i [sic] had everyone male horde at 80 already. its [sic] just fun..." ("Research on gender," Nov. 25, 2010). Similarly, Dextrall cited "variety, would be boring if I had only male toons," (“Why dudes play," June 29, 2011). 
Although most of the players in this theme pointed to a personal desire for diversity in their character list, some expressed a desire to be different in the game at large. Interviewee 002 described making mostly female characters because “...I also like to be different and you find uhm more male characters maybe than female and more uhm damage classes than healing classes and I always feel like whoever people aren't playing I want to be that," (June 6, 2011). Crysta similarly described creating a female dwarf and their joy at being one of the only ones saying:

I'm glad I did because this character was the only female dwarf on my server for quite a long time, and for longer after that I was the only Female Dwarf Priest. Even now, people crack up when I do /silly or /flirt since they either have never heard them or rarely get to hear them. ("Why did you pick," Apr. 14, 2011). Still others cited the novelty of a game that let them choose the gender of their character. Lessastorm, for example, asked "why not roll a female toon. Most games, both PC and console, have male characters as the lead. It's just the way it is as more guys play these sorts of games. It's nice to have a choice of gender for toons," ("Why dudes play," June 29, 2011). Several posters categorized under other themes also mentioned how many other games limited gender selection like many video games with set storylines and set characters who are typically male. Other games force players to be the gender they signed up as on their accounts. Still other games like Street Fighter and Dead or Alive allow the selection of characters from either gender, but those characters are tied to certainly play styles and come already designed physically. The notion of gender selection that is not tied to game play is still a relatively new idea.

\section{Conclusion}


Not only were the previously identified themes of motivation supported, but new themes emerged as data was analyzed. This lead to a total of six themes concerning the motivation for the selection of a character's gender: appearance/aesthetics, fantasy/roleplaying/immersion, perceived gendered advantages, novelty/diversity, gender identification, and no motivation. The following section provides an overview of the findings, and draws additional themes between motivations, player gender, and genderbending. 
Chapter V: Discussion and Conclusion

With more and more individuals turning to cyberspace for social interaction, this medium of communication is in need of further exploration. Specifically, video games draw a large audience of impressionable youth whose identities and conceptions about "reality" are still being shaped. The goal of this study was to investigate the practice of gender-bending in video games, specifically in a popular MMORPG called World of Warcraft. Gender-bending appears to be a common practice in such games, but the motivations have yet to be explored by academia. Through Kellner's (2003) critical analysis of media and Lanigan's (1972) thematization, forum posts, fan art, field notes, and interviews were analyzed for the motivations behind gender selection in general as well as gender-bending specifically, disparities between the genders in character gender selection, and the impacts of over-arching societal influences and game development.

\section{Trends in Gender Selection}

Generally speaking, appearance far outweighed the other themes of motivation with 330 out of 544 forum posts and eight out of ten interviews citing some aspect of appearance as a primary reason for the selection of their characters' gender. This was further supported through observations and records of informal conversations taken during the collection of field notes. Although the appearance could include a wide range of rationales, players typically cited a preference for the gear, animations, or physical appearance/build of one gender over the other. This supports much of the earlier work on appearance, demonstrating that players prefer attractive and often sexualized characters (MacCallum-Stewart, 2008; Rubenstein, 2007). The importance placed on in-game animations echoes the work of Huntemann (2009) who cited the importance of animation 
in keeping the attention of the players. However, this preference for appearance depended on other factors such as the race or class of the character chosen by the player. It is important to note, also, that players often pointed to the context-dependent nature of their rationales for gender selection; that is to say, players typically offered motivations for the gender selection of specific characters, not for the gender selection process as a whole.

The second most common motivation behind gender selection in general was that of role-playing. As a fantasy game that categorizes itself under the role-playing genre, it should come as no surprise that players identified role-playing as an influential factor in their gender selection. What is surprising is that more players did not identify this motivation, with 98 of the 544 forum posts and only two of the ten interviews referencing this rationale. Although there are a number of reasons that could be subsumed under this motivation, players typically cited playing on a role-playing specific server, the desire to follow game lore, stereotypical gender roles, or a preconceived image of their character (and possibly their back-story) as reasons for gender selection, all of which play into MacCallum-Stewart's (2008) notion of the spectacle of role-playing. Additionally, the adherence to stereotypical gender roles demonstrates the influence of the larger Western culture in which World of Warcraft is situated. These gender roles typically played out in the form of women as the nurturers or weaker individuals, and men as the strong protectors (Eagly \& Koenig, 2006).

The third most cited theme behind the motivation for gender selection was one that did not come from the preceding literature review, but rather emerged through data analysis. As data was reviewed, a need for a new category became apparent as more and more players expressed a desire for the selection of their characters' genders to coincide 
with their own. As a socialization process that begins at birth (Lorber, 1994; Butler, 1988), gender can become such a key part of individuals' identities that it is difficult for them to shed it, even in an anonymous fantasy world. Dubbed "gender identification," 88 of the 544 forum posts and four of the ten interviews referred to this motivation for the selection of their characters' genders.

The fourth most often cited motivation was that of perceived gendered advantages, with 27 of the 544 forum posts and one of the ten interviews. This motivation encompassed notions of receiving benefits from other players by playing a particular gender in the game. Rationales within this category typically referred to receiving ingame goods or help, or a higher level of politeness or respect. Stemming from Western ideals of gender roles and appropriate gender behavior (Eagley \& Koenig, 2006), players often described feeling that women received more help, a notion that was in-keeping with the previous literature (Slagel, 2006; MacCallum-Stewart, 2008; Bertozzi, 2008).

The fifth most common theme for motivation was also developed through a need seen in the data rather than the preceding literature review. This theme, dubbed “diversity/novelty," included a desire for diversity in players' personal character lists or a desire to be unique in the game at large. Typically, this novelty or diversity manifested itself in unique combinations of class, race, and gender. Of the 544 forum posts, 26 alluded to this motivation, and four of the ten interviews.

The final category, with only five of the 544 forum posts and none of the interviews was that of a complete lack of motivation for the selection of a character's gender. These were players that, in no way shape or form, cared about the gender of their in-game characters, and typically said the selection was merely coincidence or laziness to 
switch the gender on the character customization screen. However, it is important to note that although there are a number of motivations behind the selection of a character's gender, players clearly cared about the gender of their characters. Because of this clear desire for a particular gender by a large majority of players, this theme of motivation was excluded from the remaining analysis.

\section{Why Gender-Bend?}

The foregoing discussion illuminates a number of motivations for the selection of a character's gender. However, do the same motivations apply when players choose to gender-bend? The motivation of appearance remained the top choice for players genderbending with one caveat: gender identification. Although on its face the motivation of identification with one's own gender seems synonymous with selecting characters of the same gender as the player, an interesting twist emerged. Many of the individuals citing the desire for something attractive to look at showed such an identification with the heterosexual views of their own gender that it rendered them nearly incapable of playing (and by default staring at) characters of their own gender. In his discussion of the construction of self, Goffman (1959) alluded to the notion of the masks or roles assumed by individuals. These "mask," he argued, reflect only facets of an individual's personality (Goffman, 1959). With a limited number of facets that can be reflect at any one time, players are left to decide what facet is most important for them to reflect. These players often felt that excessively playing characters of their gender called into question their heterosexuality, a facet of their personality that they highly valued. Although the rational of "something attractive to look at" was classified under the motivation of appearance for its obvious association, it could arguably be put under gender identification as well. 
Perceived gendered advantages were exclusively cited by players gender-bending. Although many players cited this motivation, there was not necessarily a consensus on how each gender was treated. Typically players agreed that female characters tended to receive more help and material items, although they disagreed on which received more respect or benefit of the doubt. The former of these points is in-keeping with previous literature that highlighted Western ideas about gender roles and behavior. Eagly \& Koenig (2006), and Bertozzi (2008) argued that women are often seen as weaker, fragile individuals in Western society, and in need of protection by strong, male individuals. Thus, men, who are more likely to be aggressive and competitive with one another (Eagly \& Koenig, 2006), may assume female characters to capitalize on the societal expectations for behavioral differences in treatment of men and women.

The motivation of diversity in a player's personal character list was also almost exclusively cited by those gender-bending. Typically, these players recounted having picked predominantly characters of their own gender, and a subsequent desire for a change through gender-bending. However, those looking to be unique in the game at large were represented both by players gender-bending and those playing characters of their own gender.

The category of role-playing showed a fairly even split across the data as a whole between those playing the opposite gender and those playing the same gender. This could be due, in part, to the fact that many of these players expressed a preconceived notion of what their characters should be, thereby transcending the player's own identity. These players typically alluded to feeling that their characters were not an extension of themselves, or if they were, only a facet of a larger whole. In-keeping with previous 
literature on role-playing, fantasy games like World of Warcraft allow players to escape "reality" and assume new identities distinct from their own (MacCallum-Stewart, 2008; Yee, 2008), or to play up certain features about themselves to create an idealized version of who they are (Goffman, 1959).

\section{Different Genders, Different Motivations}

In addition to differences between players gender-bending and those playing their own gender, motivations also tended to differ between men and women. Overall, the data showed a much higher occurrence of men gender-bending than women. Although this is consistent with previous studies (Mosley \& Patrick, 2010; Huh \& Williams, 2009; Yee, July 23, 2010), previous literature has yet to provide a rationale for why men gender-bend more often than women. Even though the current data does not yet point to conclusive reasons, it does begin to illuminate some trends. Specifically, a disproportionate amount of women cited identification with their own gender as a primary motivation behind their gender selection (43\% of those citing this category of motivation were women, a large amount when compared to the overall distribution of gender in World of Warcraft). These women argued that they chose their character's gender based on their own, namely with a desire for the two to be congruent. Almost no women expressed a desire for something attractive to look at, or a fear that their sexual orientation would be called into question if they played a particular gender. Rather, they demonstrated such a deep connection between gender and their identity that they were unable to leave their own gender, even when entering a fantasy environment (Eklund, 2011). Furthermore, both male and female players alluded to an ability to break stereotypical gender norms and take on "female warrior" or "femme fatale" roles in-game. In addition to this, many women recalled being 
mistaken for men, even when playing female characters, thus making it unnecessary for them to gender-bend in order for their "real" gender to remain unknown.

For those women that chose to gender-bend, they referred almost exclusively to appearance with many females saying they particularly liked or disliked the way certain genders looked for certain races or their animations, in-keeping with feminist literature's critique of the media's emphasis on idealized bodies (Rubenstein, 2007). Very few women (a total of four) cited perceived gendered advantages as a reason to gender-bend. Of those that did, they typically reported doing so in an effort to be viewed on the merits of their skills rather than their gender, or as a means to avoid unwanted harassment (inkeeping with the work by Yee, 2008). Similarly, few women cited role-playing, although those that did tended to refer to an ability to play a strong female character.

Unlike women, the data illustrated much more willingness on the part of men to play characters of the opposite gender. Again, although not conclusive, this could be due, in part, to a process of normalization through the history of video games (MacCallumStewart, 2008). Several male players pointed to other games, arguing that it wasn't strange to play female characters in those contexts (typically where the lead, and only playable character, was female) so it shouldn't be in World of Warcraft either. As a traditionally male dominated environment, women may not have been exposed to the same process of normalization or for as long as men have.

Aside from this increased likelihood to gender-bend, men were also more likely than women to cite reasons of diversity/novelty or role-playing as a motivation for gender-bending. Men who cited diversity/novelty typically did so to refer to a desire to diversify their personal character lists by playing the opposite gender. These men 
typically cited an unwillingness to abandon their own gender in the beginning (bringing to the game outside conceptions of gender based on the socialization mentioned by Lorber, 1994 and Butler, 1988) that later waned under continued exposure to the practice of gender-bending (such as the normalization process identified by MacCallum-Stewart, 2008). However, some who referred to the notion of being unique through their class/race/gender combination did so through gender-bending. In particular, these were characters that were typically "ugly" and therefore less likely to be played by women who were looking for more aesthetic characters. In terms of role-playing, men cited stereotypically gender roles much more often than women in gender-bending. Although some men remarked about a desire to play a strong female character, many men turned to the stereotypically notion of women as the care-givers (healing classes) or weaker attackers (choosing casters for female characters over melee classes) (Yee, Ducheneaut, Yao, \& Nelson, 2011).

However, appearance remained the top motivating factor for men in choosing the gender of their characters, regardless of whether they were playing characters of the opposite or same gender as themselves. Again, this brings up the notion of gender identification among men who chose to gender-bend because of a firm identification with heterosexual male views. However, this theme left male players divided; some players said it was less heterosexual to play female characters, comparing it to playing with Barbie dolls, while others said it was less heterosexual to stare at male characters for hours on end. This same argument was not seen among female players, and no female players cited playing male characters for fear of their heterosexuality being questioned.

\section{Gender-Bending: Deviant Behavior?}


Although there appeared to be a rift over whether playing characters of the same or opposite gender for men was more or less "heterosexual," ultimately players argued a "play what you like" sort of view. Many players pointed to the fact that World of Warcraft is, in fact, a fantasy game, saying that it's no less deviant to play a character of the opposite gender than it is to play a race other than human. Along these same lines, players espoused a view that in-game personas had no bearing on their "real" identities (supported by the work of MacCallum-Stewart, 2008). Furthermore, several players alluded to having played characters of the opposite gender in other video games. Although many of the games the players referred to had a limited number of characters with set characteristics, the point still stood that it was no more deviant to play a character of opposite gender when players had a choice, than when players did not. This argument is in-keeping with the work by MacCallum-Stewart (2008) who argued that the evolution of video games and their characters facilitated a process of normalization of gender-bending beginning in games were there was no choice for character gender, and ending in games where gender had no bearing on the mechanics of the game. Ultimately, although a number of motivations were offered for gender selection, all appeared to be viewed as relatively equal and acceptable by the community of World of Warcraft.

Although all motivations appeared to be relatively equal in the eyes of the World of Warcraft community, many players remarked on a double standard for genderbending. Specifically, although gender-bending was much less common among women than men, many players remarked that women gender-bending seemed less acceptable. Interviewee 001 (June 5, 2011) argued that this was in-keeping with notions that the majority decides how actions will be viewed; Because World of Warcraft is a 
predominantly male community, he maintained, men typically decided what was and was not acceptable (regardless of whether this was right or fair). Thus, gender-bending for men was acceptable, where gender-bending for women was not. Even female players remarked that the notion of playing male characters seemed, in some ways, "wrong" to them. However, it should be noted that although a large number of players viewed gender-bending by women as deviant, an almost equal number viewed it as strange but were nonetheless open to it.

Although gender-bending in general was seen as an acceptable behavior, players demonstrated a keen awareness that society at large might view this sort of behavior as deviant. Demu, for example, remarked "it's a game, it means nothing and by that, no-one should be called a transvestite for having a character of the opposite gender," ("Why dudes play,” June 29, 2011) Similarly, Pixiekiller poked fun at this notion saying “...I am a homosexual and get a big buzz out of cybering with heterosexual teenage boys. Well, that is what my wife tells me," ("Why dudes play," June 29, 2011). The problem with this perception, however, is that this sort of behavior (taking on the opposite gender) online cannot be compared to this sort of behavior in the world at large. From a theoretical standpoint, World of Warcraft constitutes its own, unique culture with its own set of meanings (Ramet, 1996). Taking on the opposite gender in-game does not carry the same set of feelings or beliefs as doing so in everyday life. The preceding motivations highlight the majority of the rationales players used when selecting their characters' genders, none of which displayed a sense of identification with the other gender. If anything, these motivations demonstrate a connection with players' own gender or pragmatic reasons for assuming the other gender (such as appearance or perceived benefits). 


\section{The Influence of Political Economy and In-Game Imagery}

The contributions of an analysis of political economy and textual analysis (predominantly through the medium of in-game imagery) provide an interesting backdrop on which to position the foregoing findings. However, aside from providing a better understanding of the influences that led to some of the aforementioned findings, they point to two things in particular. Political economy illustrates the process of normalization for gender-bending among men. As a traditionally male dominated industry, video games were (and still are) primarily developed by men for men. This means that these developers planted the first seeds of gender-bending by designing games with playable female characters that were still mostly geared toward a male audience (MacCallum-Stewart, 2008).

The textual analysis of in-game imagery provides further support for the importance of appearance in World of Warcraft. With the obvious in-game emphasis on sexualization and ideal body types (Rubenstein, 2007; Corneliussen, 2009), it should come as no surprise that players reflected an equal level of importance placed on appearance. Specifically, characters displayed a high level of sexualization with the female character body types ranging from super model to female athlete, and the males ranging from slim to large body builder (Rubenstein, 2007). This also reflected the larger Western ideal of the importance of beauty (Rubenstein, 2007), and demonstrates the cultural interconnectedness between World of Warcraft, the video game industry, and American culture.

\section{Implications}


The foregoing discussion highlighted themes of motivation, and the differences between these themes (and their uses) based on player gender and whether or not the player engaged in gender-bending. However, these findings are specific to the small sample of World of Warcraft players on American and European servers. Despite this, a larger picture can be drawn, and more general implications can be articulated.

Much like Butler (1988) and Lorber (1994) described women as undergoing a different process of socialization than that of men, one which ultimately dictated their societal roles, behavior, and rules for interaction, female gamers can be seen to have undergone a different process of normalization in regards to gender-bending. Specifically, as an industry developed by men for a male audience, video games have always catered to that majority, and thus the process of normalization with the first introduction of female characters began primarily with male gamers. Women, still being new to and a minority among video game communities, have had less exposure to this process and thus may not reflect the same level of comfort with it. However, in society at large, women have traditionally had to fight for equality, whether it be for equal pay, equal rights to voice opinions, or equality in education. To be a woman has meant to fight and struggle on behalf of women everywhere, and for the gender as a whole. This means that for women, being a woman is a defining part of their identity; it's what society has told them they are defined by their whole lives, and is one of the primary reasons they must fight for equality. After years of socialization and struggle, women are reluctant to leave what they feel to be a defining feature of who they are behind, even at the supposedly liberating gates of a fantasy world. The female World of Warcraft players from this sample frequently demonstrated this attachment by citing and emphasizing their 
gender as a key motivation for their characters' gender selection. Additionally, many of these women, and even men, described playing a female character as empowering, allowing them to be a strong woman in a way they could not be in the "real" world.

Although women seemed to cling most closely to their sex as a defining piece of their identity, men seemed to value their sexual orientation more highly than their sex in how they conceived themselves. This was evidenced by the large number of male World of Warcraft players citing the importance of an attractive female avatar to stare at over hours of game-play, and the rationale that this was somehow less "gay" than staring at a male character. As a society, Western culture teaches young girls that they are the weaker sex, and that anyone taking on feminine qualities (such as homosexuals are stereotypically portrayed to do) is weak as well (Bertozzi, 2008). Thus, men are already the stronger sex, and are encouraged to assert their masculinity as further evidence of their strength and superiority. Already having the upper hand in terms of societal views of sex traits, men must instead defend their heterosexuality to reaffirm their position as the stronger sex.

Through this adherence to gender and its societally assigned traits, gamers in general have demonstrated a cross over in values between society at large and the video game world. Much of their behavior reflects Western norms and rules of interactions such as chivalry and the construction of gender roles in-game (Eagly and Koenig, 2006; Bertozzi, 2008). In the current sample, a number of players described their gender selection as based on stereotypical roles dictated by larger Western society, such as women as nurturers and men as aggressive protectors. These preceding allusions to gender online and the influence of Western society on these constructions and enactments 
of gender demonstrate the permeability between the worlds of fantasy and cyberspace, and physical societies.

Although video games represent unique cultures whose values, beliefs, rules, and understandings cannot be assumed to be the same, nor serve the same functions, as the larger, physical societies from which they arise, there is certainly a degree of mutual influence. That is, cultures exert a flow, both internally and externally, influencing components within itself and other cultures around it. Video games like World of Warcraft are influenced by the Western culture from which they and their players arise; developers create games based on the ideologies to which they and their audience are accustomed, and players filter their experiences through some of the larger societal systems of meaning they have been socialized to rely on. However, players create communities of gamers who share common experiences through the game, and create new and varied ways to interpret these based on their electronic fantasy worlds. Just as Western culture influences and embeds itself in video games, the players carry their newfound understandings and interpretations into Western society. As more and more individual turn to cyberspace and the virtual worlds of video games, these lines between physical Western society and online video game cultures will continue to blur. Will these boundaries shift, how far, and what will be the affect of such a shift on both the physical cultures and the virtual ones? These are all questions that future research will need to address, as the flow of cultures continues to ebb and flow in a cyclical process of influence.

\section{Limitations}


As with any study, this study is not without its limits. One of the larger limits is that no female players were recruited for the interviewing process. This is not to say that attempts were not made to recruit and interview females, but for one reason or another it never seemed to work out. Similarly, a limit of the forum post data was that not all posters identified their gender in their posts. Some did, and others did so implicitly, but many did not, instead simply voicing their opinion with little to no background on themselves. That data set could have been strengthened if the opportunity to ask posters for their real gender had been available. Finally, the study as a whole could have benefited from a larger sample of interviews to provide a more in-depth look than the forum postings allowed.

\section{Contributions}

This study contributes to the current body of literature by reinforcing pre-existing themes of motivation for gender selection, as well as adding new ones. These new themes expand the existing view on the gender selection process in video games to incorporate new perspectives that were either absent or not explicitly articulated. Furthermore, this study focuses additional attention on the notion of gender-bending, and whether motivations for gender selection in general hold up in instances of gender-bending.

Additionally, this study challenges some of the existing literature that compares gender-bending in video games to cross-dressing in "real" life. Such comparisons are, in my opinion, dangerous, as are any evaluations made on one culture using the standards of another. World of Warcraft is, in many ways, a culture in and of itself; it has a language, a set of rules that govern behavior and interactions, and a set of meanings through which players understand each other. This study has demonstrated that players are aware that 
society at large often brands their gender-bending as deviant behavior. Yet it also demonstrates their rebuke of such a label.

\section{Future Research}

Future research should continue to address gender-bending in video games, and look to reinforce or add to the themes of motivation. However, it should also expand to look at how gender-bending affects players' conceptions of gender and how it may affect such views in the world at large. Such views about gender and media are often cyclical: our views are influenced by the media we're exposed to, and we, in turn, influence that media. This begs the question, then, how this increasing exposure to gender-bending may be affecting societies' views about gender, what it means to be male or female, and how each gender should behavior. These affects raise an especially important point because of the young audiences video games target. Because many teenagers and young adults, whose views and conceptions about things like gender and appropriate behavior are still being formed, video games provide one of a number of environments in which these individuals learn how to act and what to think. It is because of this that researchers need to pay particular attention to youth and video games. Not only do video games influence youth, but those youth, in turn, influence the games they play. Thus, such research not only offers insight into the minds of the current generation, but presents a trajectory for future cultural changes and ways of understanding.

\section{Conclusion}

The World of Warcraft is a large world, encompassing over twelve million players from different cultures, generations, levels of education, and backgrounds. Yet, despite these differences, World of Warcraft is a culture all its own in which players 
negotiate their interactions with shared cultural experiences and knowledge. One such experience is that of gender selection for characters. Through an analysis of previous literature and a study of forum posts, field notes, fan art, and interview with players, this study highlighted six themes of motivation for the selection of a character's gender: appearance, role-playing/fantasy, gender identification, perceived gendered advantages, novelty/diversity, and no motivation. These themes varied in their use when applied to gender-bending, and varied by players' actual gender. However, these motivations did not develop on their own. Rather, a careful analysis of the cultural position of the game showed influences from the larger American popular culture, the video game industry, and the history of both. Despite the contributions of this study, future research is necessary to continue expanding an understanding of gender-bending as a video game phenomena. 
References

(2008). She's Got Game: Women in the Video Game Industry. Retrieved from http://careerpronews.bridges.com/explorer/browse/et/womanvid/main.htm

(2010, Nov. 25). Research on gender and gaming. Forum thread from http://us.battle.net/wow/en/forum/topic/1127483790

(2010, Dec. 2). Wrong gender characters, weird? Forum thread from http://us.battle.net/wow/en/forum/topic/1208031016

(2011, Apr. 13). Why did you pick your race/gender. Forum thread from http://us.battle.net/wow/en/forum/topic/2369881310

(2011, June 29). Why dudes play on Female characters? Forum thread from http://eu.battle.net/wow/en/forum/topic/2290802117

Becker, H.S. (2001). The epistemology of qualitative research, in R.M. Emerson (Ed.), Contemporary Research: Perspectives and Formulations ( $2^{\text {nd }}$ ed., pp. 317-330). Prospect Heights, IL: Waveland Press Inc.

Bertozzi, E. (2008). 'You play like a girl!' : Cross-gender competition and the uneven playing field. Convergence: The International Journal of Research into New Media Technologies, 14, 473-487.

Blizzard Entertainment. (2010). World of Warcraft Subscriber Base Reaches 12 Million Worldwide. Retrieved from http://us.blizzard.com/enus/company/press/pressreleases.html?101007

Brookey, R.A. \& Cannon, K.L. (2009). Sex lives in second life. Critical Studies in Media Communication, 26 (2), 145-164. 
Corneliussen, H.G. (2009). World of Warcraft: Non-fantasy gender in a high-fantasy world. National Sexuality Resource Center, retrieved from http://nsrc.sfsu.edu/article/world_warcraft_non_fantasy_gender_high_fantasy_wo rld.

Dietz, T.L. (1998). An examination of violence and gender portrayals in video games: Implication for gender socialization and aggressive behavior, Sex Roles, 38 (516), 425-442.

Ducheneaut, N. (2010, July 23). Reliable, scalable in-game data collection. PlayOn: Exploring the Social Dimensions of Virtual Worlds. Retrieved from http://blogs.parc.com/playon/2010/07/23/reliable-scalable-in-game-datacollection/.

Ducheneaut, N., Wen, M.D., Yee, N., \& Wadley, G. (2009). Body and mind: A study of avatar personalization in three virtual worlds. Paper presented at CHI, Boston Massachusetts.

Eagly, A.H. \& Koenig, A.M. (2006). Social role theory of sex differences and similarities: Implications for prosocial behavior in K. Dindia \& D.J. Canary (Eds.), Sex Differences and Similarities in Communication (2 ${ }^{\text {nd }}$ Ed., pp. 156-172). Lawrence Erlbaum Associates.

Eklund, L. (2011). Doing gender in cyberspace: The performance of gender by female World of Warcraft players. Convergence: The International Journal of Research into New Media Technologies. 17(3), 323-342. 
Ellis, C. (1997). Evocative autoethnography: Writing emotionally about our lives. In W.G. Tierney \& Y.S. Lincoln Representation and the Text: Re-Framing the Narrative Voice (pp. 115-142). Albany, NY: State University of New York Press.

Ellis, C., \& Bochner, A. (2000). Autoethnography, personal narrative, reflexivity: Researcher as subject. In N. Denzin \& Y. Lincoln (Eds.), The Handbook of Qualitative Research ( $2^{\text {nd }}$ ed., pp. 733-768). Thousand Oaks, CA: Sage.

Emerson, R. M. (2001). The face of contemporary ethnography, in R.M. Emerson (Eds.), Contemporary Research: Perspectives and Formulations ( $2^{\text {nd }}$ ed., pp. 27-54). Prospect Heights, IL: Waveland Press Inc.

Entertainment Software Association. (2009). Essential Facts About the Computer and Video Game Industry. Retrieved from http://www.theesa.com/facts/pdfs/ESA_EF_2009.pdf.

Fahs, T. (2009). IGN presents the history of Wacraft: The battle for Azeroth rages on. IGN. Retrieved from http://retro.ign.com/articles/101/1014622p1.html.

Fantone, L. (2009). Female players from margin to centre: Female sociality, digital consumer citizenship and reterritorialisations. Digitial Creativity, 20 (4), 211-224.

Geertz, C. (2001). Thick description: Toward an interpretive theory of culture, in R.M. Emerson Contemporary Research: Perspectives and Formulations $\left(2^{\text {nd }}\right.$ ed., pp. 55-75). Prospect Heights, IL: Waveleand Press Inc.

Goffman, E. (1959). The presentation of self in everyday life, in C.J. Calhoun, J. Gerteis, J. Moody, S. Pfaff, \& I. Virk (Eds.), Contemporary Sociological Theory $\left(2^{\text {nd }}\right.$ ed., pp. 52-66), Malden, MA: Blackwell Publishing. 
Gourdin, A. (2005). Game Developer Demographics: An Exploration of Workforce Diversity, retrieved from http://archives.igda.org/diversity/IGDA_DeveloperDemographics_Oct05.pdf.

Greenberg, B. (2004). Children spend more time playing video games than watching TV. Retrieved from http://news.msu.edu/story/466/.

Horkheimer, M. \& Adorno, T.W. (2002). Dialectic of Enlightenment G.S. Noerr (Ed.). (E. Jephcott, Trans.). Stanford, CA: Stanford University Press. (Original work published 1969).

Huh, S. \& Williams, D. (2010). Dude looks like a lady: Gender swapping in an online game in W.S. Bainbridge Online Worlds: Convergence of the Real and the Virtual (pp. 161-174). New York, NY: Springer.

Huntemann, N. (2009). Pixel pinups: Images of women in video games in R.A. Lind (Eds.), Race/Gender/Media: Considering Diversity Across Audiences, Content, and Producers ( $2^{\text {nd }}$ ed., pp. 250-257). Boston, MA: Pearson.

Klepek, P. (2005, June 16). Dead or alive on film: Cory Yuen of the transporter to direct game adaptation. 1Up. Retrieved from http://www.1up.com/news/dead-alive-film.

Lincoln, Y.S. \& Guba, E.G. (1985). Naturalistic Inquiry. Newbury Park, CA: Sage Publications.

Lanigan, R. (1972). Speaking and Semiology: Maurice Merleau-Ponty's Phenomenological Theory of Existential Communication. The Hague: Mouton Lanigan, R. (1975). Existential Speech and the Phenomenology of Communication. Retrieved from http://www.eric.ed.gov/PDFS/ED103921.pdf 
MacCallum-Stewart, E. (2008). Real boys carry girly epics: Normalising gender bending in online games. Journal for Computer Game Culture, 2 (1), 28-36.

Martey, R.M. \& Consalvo, M. (2011). Performing the looking-glass self: Avatar appearance and group identity in Second Life. Popular Communication, 9 (3), 165-180.

McLaughlin, R. (2008, February 29). IGN presents: The history of tomb raider. IGN. Retrieved from http://retro.ign.com/articles/856/856183p1.html.

Mosley, I.D. \& Patrick, S. (2010). Personality and character selection in World of Warcraft, McNair Scholars Research Journal, 6 (1), 57-63.

Newcomb, H. \& P.M. Hirsch (1983). Television as a cultural forum, Quarterly Review of Film Studies, Summer, 561-573.

Patton, M.Q. (2002). Qualitative Research and Evaluation Methods ( $3^{\text {rd }}$ ed.). Thousand Oaks, CA: Sage Publications Inc.

Purchese, R. (2010, June 8). Tekken 6 breaks 3 million sales. Eurogamer. Retrieved from http://www.eurogamer.net/articles/2010-08-06-tekken-6-breaks-millionmarker.

Ramet, S.P. (1996). Gender reversals and gender cultures: An introduction in S.P. Ramet (Ed.), Gender Reversals \& Gender Cultures (pp. 1-21). New York, NY: Routledge.

Rettberg, S. (2008). Corporate ideology in World of Warcraft in H. Corneliussen \& J.W. Rettberg (Eds.), Digital Culture, Play, and Identity: A World of Warcraft Reader (pp. 19-38). MA: Massachusetts Institute of Technology. 
Rubenstein, A. (2007). Idealizing fantasy bodies, Iris Gaming Network: Subverting the Status Quo On Gamer at a Time. Retrieved from http://theirisnetwork.org/2007/05/26/idealizing-fantasy-bodies/

Ryle, R. (2011). Questioning Gender: A Sociological Exploration, Thousand Oaks, CA: Pine Forge Press.

Sanbonmatsu, J. (2011). Video games and machine dreams of domination, in G. Dines \& J.M. Humez (Eds.) Gender, Race, and Class in the Media: A Critical Reader $\left(3^{\text {rd }}\right.$ ed., pp. 427-436). Thousand Oaks, CA: Sage Publications Inc.

Schut, K. (2007). Strategic simulations and our past: The bias of computer games in the presentation of history. In G. Dines \& J.M. Humez (Eds.) Gender, Race, and Class in the Media: A Critical Reader ( ${ }^{\text {rd }}$ ed., pp. 437-442). Thousand Oaks, CA: Sage Publications Inc.

Schwartzman, H.B. (1993). Ethnography in Organizations. Newbury Park, CA: Sage Publications Inc.

Shaw, A. (2010). What is video game culture? Cultural studies and game studies. Games and Culture, 5 (4), pp. 43-424.

Slagle, M. (2006). Gender-bending popular in video games: Male players say female characters have distinct gameplay advantage. MSNBC Science and Technology. Retrieved from http://www.msnbc.msn.com/id/14304639/ns/technology_and_sciencegames/t/gender-bending-popular-video-games/ 
Slimmer, J. (2007). Kings, queens, and jackasses: Playing with gender in online poker. FlowTV. Retrieved from http://flowtv.org/2007/02/kings-queens-and-jackassesplaying-with-gender-in-online-poker/.

Vella, M. (2008). Inside the world of Blizzard. Business Week. Retrieved from http://www.businessweek.com/innovate/content/aug2008/id20080820_123140.ht m.

Waem, A., Larsson, A., \& Neren, C. (2005). Gender aspects on computer game avatars. Paper presented at the ACM SIGCHI International Conference on Advance in Computer Entertainment Technology at the Swedish Institute of Computer Science, Valencia Spain.

Williams, D., Kennedy, T.L.M., \& Moore, R.J. (2011). Behind the avatar: The patterns, practices, and functions of role playing in MMOs. Game and Culture. 6 (2), 171200.

Williams, R. (2001). Television and representation, in J. Higgins (Ed.) The Raymond Williams Reader (pp. 179-187). Malden, MA: Blackwell Publishers Inc. (Original work published in 1974).

Williams, R. (2003). The technology and the society, in T. Miller (Ed.), Television: Critical Concepts in Media and Cultural Studies (pp. 42-57). New York, NY: Routledge (Original work published in 1978).

Yee, N. (2008). Maps of digital desires: Exploring the topography of gender and play in online games. In Kafai, Y., Heeter, C., Denner, J. \& Sun, J. (Eds.), Beyond Barbie and Mortal Kombat: New Perspectives on Gender and Gaming (pp. 82-95). Cambridge, MA: MIT Press. 
Yee, N. (2008, August 4). Avatar survey: Time spent in-world and customizing avatar. PlayOn: Exploring the Social Dimensions of Virtual Worlds. Retrieved from http://blogs.parc.com/blog/2008/08/avatar-survey-time-spent-in-world-andcustomizing-avatar/.

Yee, N. (2010, July 23). Gender bending. PlayOn: Exploring the Social Dimensions of Virtual Worlds. Retrieved from http://blogs.parc.com/playon/2010/07/23/genderbending/.

Yee, N. (2010, July 23). Overview of participants. PlayOn: Exploring the Social Dimensions of Virtual Worlds. Retrieved from http://blogs.parc.com/playon/2010/07/23/overview-of-participants/.

Yee, N. (2010, August 2). Game-play motivations. PlayOn: Exploring the Social Dimensions of Virtual Worlds. Retrieved from http://blogs.parc.com/playon/2010/08/02/game-play-motivations/.

Yee, N. (2010, December 8). Character race when gender-bending. PlayOn: Exploring the Social Dimensions of Virtual Worlds. Retrieved from http://blogs.parc.com/playon/2010/12/08/character-race-when-gender-bending/.

Yee, N., Bailenson, J.N., Urbanek, M., Chang, F., \& Merget, D. (2007). The unbearable likeness of being digital: The persistence of nonverbal social norms in online virtual environments. Cyberpsychology and Behavior, 10 (1), p. 115-121.

Yee, N., Ducheneaut, N., Yao, M., \& Nelson, L. (2011). Do men heal more when in drag? Conflicting identity cues between user and avatar. Paper presented at $\mathrm{CHI}$, Vancouver BC, Canada. 


\section{Appendix A}

Interview Guide

Name:

Age:

Gender:

Length of time playing World of Warcraft:

1. How did you first become interested in video games, generally speaking?

2. How did you become interested in World of Warcraft specifically?

3. Can you please describe, in detail, the characters you play the most often and would consider your "mains?" Specifically characteristics like race, gender, class, level, general level of gear, etc.

4. Of the characters that you described as the same gender as you, why did you choose that gender for those characters?

5. Of the characters that you described as being the opposite gender from you, why did you choose that gender for those characters?

a. (For those players that create characters exclusively of one gender) Why did you choose not to make any male/female characters?

6. When playing World of Warcraft, how do you think the appearance of your avatar(s), specifically the gender, affects your interactions with other players? Do you think the appearance has an affect?

7. What do you think other players think when they discover you're playing a character of the opposite gender?

a. Do you think this realization affects your interactions with that player?

8. Does it make a difference if it's a male playing a female character versus a female playing a male character? 
Appendix B

Letter of Informed Consent

Dear Participants:

You are invited to participate in a research study conducted by Claire Gregory in conjunction with the Portland State University Department of Communication. This study's aim is to investigate the effects of avatar appearance on interactions in the popular video game, World of Warcraft. If you decide to participate, you will be asked to take part in a short interview (approximately 30-45 minutes) lasting approximately 30-45 minutes. This interview will be audio recorded, but will be kept confidential with no disclosure of your identity or your information outside of those directly involved in the research.

If at any time you feel uncomfortable or would like to stop the interview, you may do so. Your participation in this study is completely voluntary, and you retain the right to withdraw at any time. All information disclosed in this process will be kept confidential, but the information and direct quotes may be used for scholarship such as papers or publications. However, your identity will never be disclosed and all participants will be assigned a pseudonym.

If you have any concerns about your rights as a participant, or about your participation in this study, please feel free to contact the Human Subjects Research Review Committee, Office of Research and Sponsored Projects, 600 Unitis Building, Portland State University, (503) $725-4288$ or 1-877-480-4400. For questions regarding the study itself, please feel free to contact Claire Gregory at crgregor@pdx.edu.

Thank you for your participation and cooperation. 

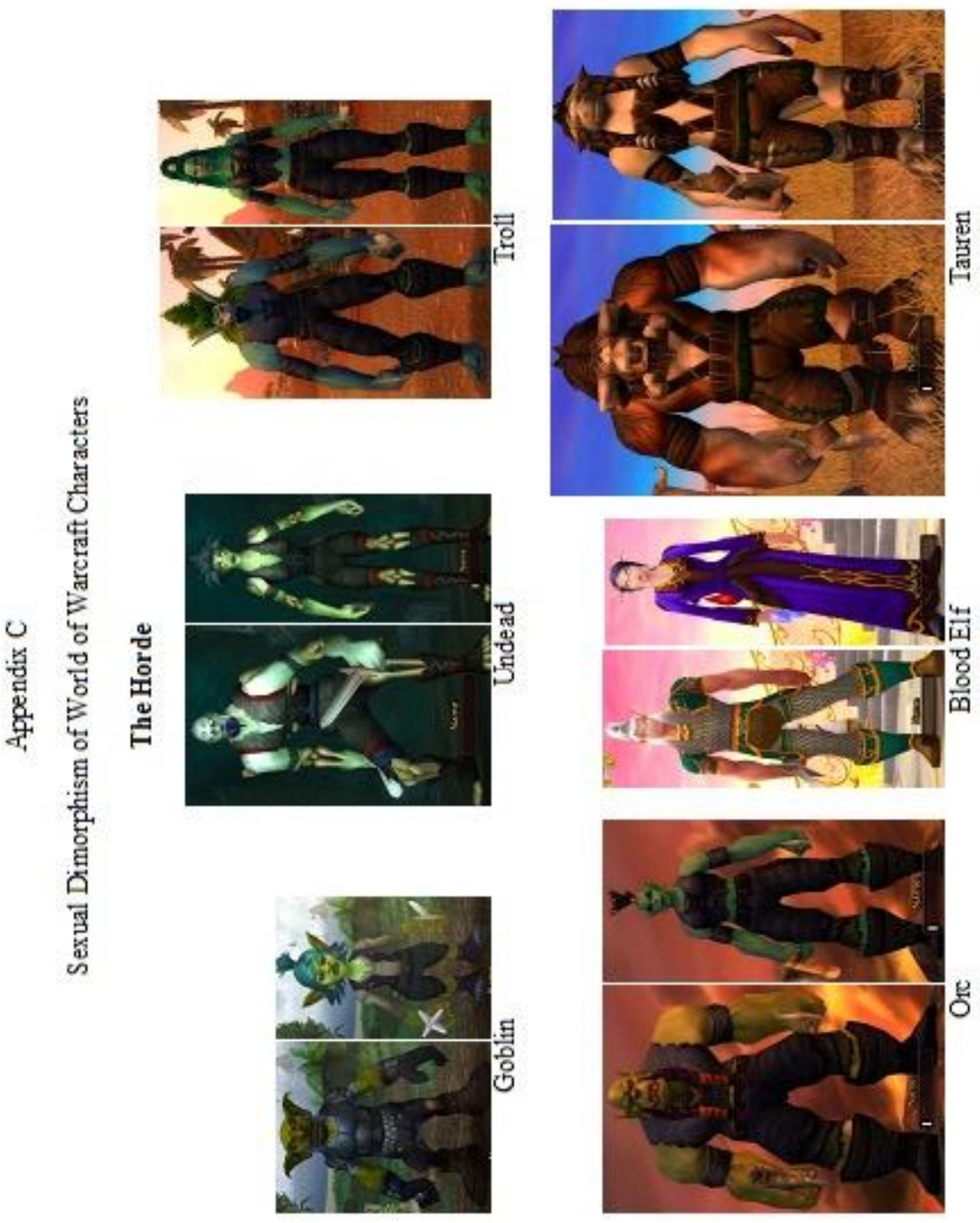

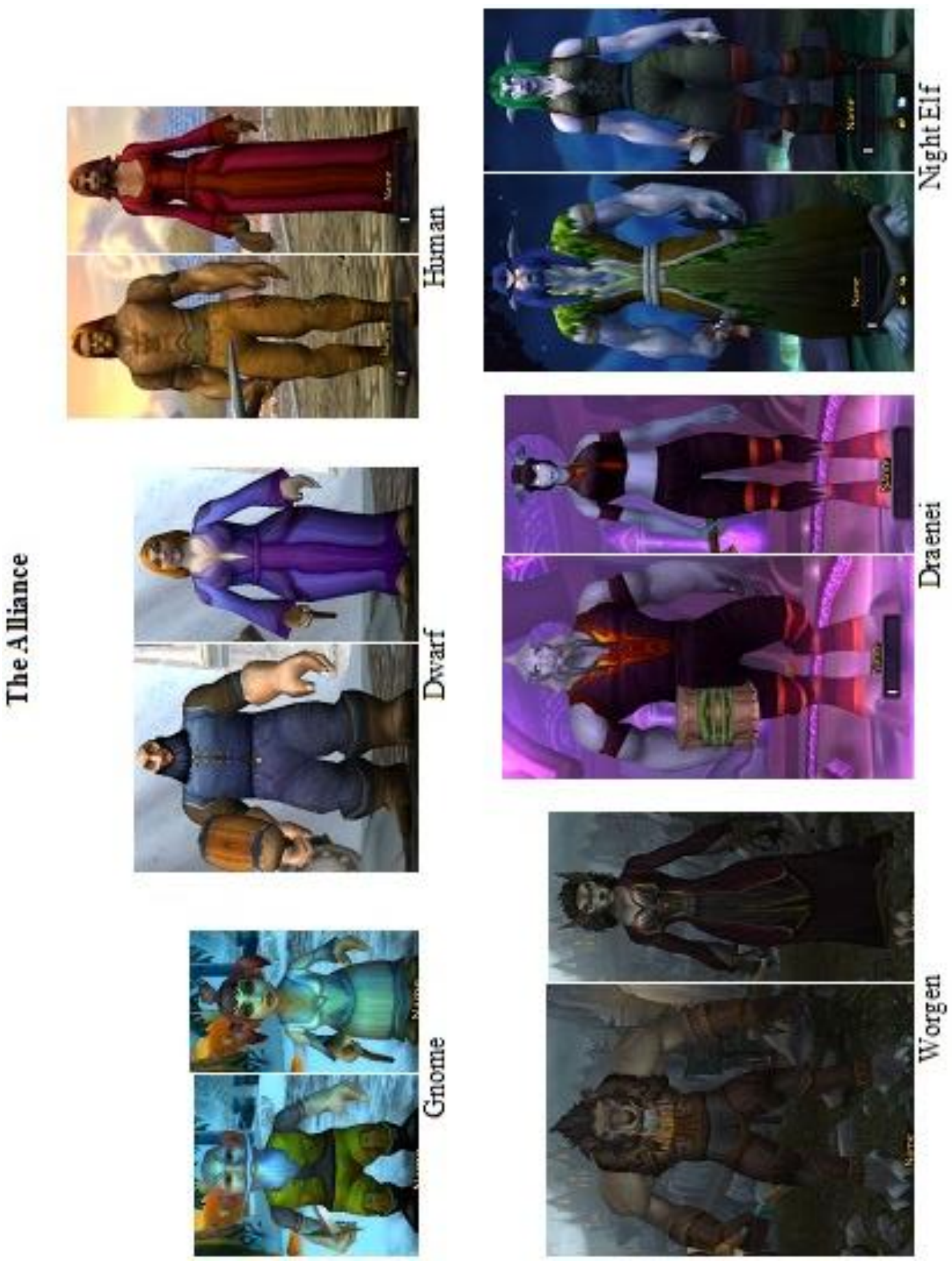